\title{
TYK2 licenses non-canonical inflammasome activation during endotoxemia
}

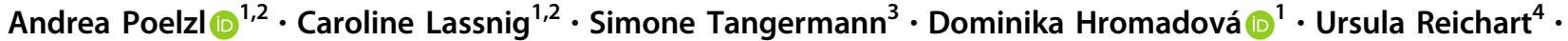 \\ Riem Gawish $^{1} \cdot$ Kristina Mueller $^{1} \cdot$ Richard Moriggl $^{1} \cdot$ Andreas Linkermann $^{5} \cdot$ Martin Glösmann $^{4} \cdot$ Lukas Kenner $^{3}{ }^{3}$. \\ Mathias Mueller ${ }^{1,2} \cdot$ Birgit Strobl $\mathbb{1}^{1}$
}

Received: 7 January 2020 / Revised: 31 August 2020 / Accepted: 1 September 2020 / Published online: 14 September 2020

(c) The Author(s), under exclusive licence to ADMC Associazione Differenziamento e Morte Cellulare 2020

\begin{abstract}
The non-canonical inflammasome is an emerging crucial player in the development of inflammatory and neurodegenerative diseases. It is activated by direct sensing of cytosolic lipopolysaccharide (LPS) by caspase-11 (CASP11), which then induces pyroptosis, an inflammatory form of regulated cell death. Here, we report that tyrosine kinase 2 (TYK2), a cytokine receptorassociated kinase, is a critical upstream regulator of CASP11. Absence of TYK2 or its kinase activity impairs the transcriptional induction of CASP11 in vitro and in vivo and protects mice from LPS-induced lethality. Lack of TYK2 or its enzymatic activity inhibits macrophage pyroptosis and impairs release of mature IL- $1 \beta$ and IL-18 specifically in response to intracellular LPS. Deletion of TYK2 in myeloid cells reduces LPS-induced IL-1 $\beta$ and IL-18 production in vivo, highlighting the importance of these cells in the inflammatory response to LPS. In support of our data generated with genetically engineered mice, pharmacological inhibition of TYK2 reduced LPS-induced upregulation of CASP11 in bone marrowderived macrophages (BMDMs) and of its homolog CASP5 in human macrophages. Our study provides insights into the regulation of CASP11 in vivo and uncovered a novel link between TYK2 activity and CASP11-dependent inflammation.
\end{abstract}

Edited by C Borner.

Supplementary information The online version of this article (https:// doi.org/10.1038/s41418-020-00621-x) contains supplementary material, which is available to authorized users.

$\triangle$ Birgit Strobl

birgit.strobl@vetmeduni.ac.at

1 Institute of Animal Breeding and Genetics, University of Veterinary Medicine Vienna, 1210 Vienna, Austria

2 Biomodels Austria, University of Veterinary Medicine Vienna, 1210 Vienna, Austria

3 Unit of Laboratory Animal Pathology, University of Veterinary Medicine Vienna, 1210 Vienna, Austria

4 VetCORE - Facility for Research, University of Veterinary Medicine Vienna, 1210 Vienna, Austria

5 Division of Nephrology, Department of Internal Medicine III, University Hospital Carl Gustav Carus at the Technische University of Dresden, 01069 Dresden, Germany

\section{Introduction}

Tyrosine kinase 2 (TYK2) is a member of the Janus kinase (JAK) family of receptor-associated tyrosine kinases, which mediates signalling by a large number of cytokines and some growth factors. TYK2 is ubiquitously expressed and transduces responses to cytokines that utilize the type I interferon (IFN) receptor chain 1 (IFNAR1), interleukin-10 receptor 2 (IL-10R2), IL-12R $\beta 1$, and IL-13R $\alpha 1$. TYK2 drives immunity to viral and bacterial infections in humans and mice [1-3]. By contrast, TYK2 aggravates inflammatory and autoimmune diseases, as established by studies with TYK2-deficient $\left(T y k 2^{-/-}\right)$mice and supported by genome-wide association studies (GWAS) in humans [4]. TYK2 inhibitors have been developed for the treatment of inflammatory diseases, with some of them being already investigated in clinical trials [5, 6]. In addition to its functions as signal-transducing kinase, TYK2 has functions that do not rely on its enzymatic activity, although these are still incompletely understood [3, 7-9]. A better understanding of how TYK2 integrates signalling inputs in different pathophysiological conditions and which of its functions depend on enzymatic activity is urgently needed. 
Inflammatory responses are essential for the host defence against pathogens but, if unbalanced, can lead to septic shock and multiorgan failure. The pathogenesis of severe systemic inflammation is not fully understood and remains a major problem in health care due to high mortality rates [10]. Lipopolysaccharide- (LPS-) induced endotoxemia is an experimental model of hyperinflammation induced by Gram-negative bacterial compounds $[10,11]$. Tyk $2^{-/-}$mice are protected from LPS-induced endotoxin shock [12-14]. The underlying mechanisms are largely unknown but have been linked to the role of TYK 2 in IFN $\alpha / \beta$ signalling, including the induction of IL-27p28, and IL-12-mediated induction of IFN $\gamma$ [12-14]. We have shown previously that TYK2 suppresses pro-IL1 $\beta$ production at the translational level by IFN $\alpha / \beta$-dependent mechanisms, which correlates with an increase in IL-1 $\beta$ release upon activation of the canonical NLRP3 (NLR family pyrin domain containing 3) inflammasome in $T y k 2^{-/-}$macrophages and increased local, but not systemic, IL-1 $\beta$ at early time points after LPS challenge in vivo [15].

In this study, we used $T y k 2^{-1-}$ mice and mice that express kinase-inactive TYK2 (Tyk2 $2^{K 923 E}$ mice) to investigate the role of TYK2 and its enzymatic activity in the pathogenesis of endotoxemia. We uncovered a crucial role of TYK2 signalling in the induction of caspase-11 (CASP11) and the non-canonical inflammasome-dependent release of IL-1 $\beta$ and IL-18. We provide evidence that during endotoxemia this pro-inflammatory function of TYK2 is mainly exerted by myeloid cells (i.e. LysMpositive cells). In line with the genetic deletion or inactivation of TYK2, pharmacological inhibition of TYK2 in macrophages markedly inhibited LPS-induced upregulation of murine CASP11 and its human homolog CASP5. Our data suggest that the absence or inactivation of TYK2 protects from inflammation-associated mortality by impairing the upregulation of CASP11, the central component of the non-canonical inflammasome.

\section{Methods}

\section{Mice and ethics statement}

Wild-type (WT, C57BL/6N; purchased from Charles River Laboratories), Ty $k 2^{-/-}, T y k 2^{K 923 E}, T y k 2^{f l f l}, T y k 2^{\Delta L y s M}$, Ifnarl ${ }^{-/-}$and Ifngrl ${ }^{-/-}$mice [16-20] were bred at the University of Veterinary Medicine Vienna under specificpathogen-free conditions according to Federation of European Laboratory Animal Science Associations (FELASA) guidelines. All animal experiments were approved by the ethics and animal welfare committee of the University of Veterinary Medicine Vienna and the national authority (Austrian Federal Ministry of Science and Research) according to $\S \S 26 \mathrm{ff}$. of Animal Experiments Act, Tierversuchsgesetz 2012_-TVG 2012 (BMWFW-68.205/0032$\mathrm{WF} / \mathrm{II} / 3 \mathrm{~b} / 2014$ ) and conform to the guidelines of FELASA and ARRIVE (Animal Research: Reporting of In Vivo Experiments).

\section{In vivo LPS challenge}

Age-matched (8-12-weeks-old) female mice on C57BL/ $6 \mathrm{~N}$ background were used for all experiments. Mice were injected intraperitoneally (i.p.) with $50 \mathrm{mg} / \mathrm{kg}$ LPS from Escherichia coli 055:B5 (Sigma) in 200 $\mu \mathrm{l}$ PBS or with PBS only as control. Depending on the read-out, blood and organs were harvested after 2, 6, 16 or $24 \mathrm{~h}$. Survival was monitored for 7 days, body weight and the body temperature of the mice (rectal temperature) was determined twice daily. Severity of disease was assessed on the basis of an established scoring system, including criteria such as appearance (eyes, coat/fur), mobility, behaviour, posture and response to external stimuli. Humane endpoint by cervical dislocation was conducted upon reaching the threshold sickness score. Animal experiments were performed by trained and authorized personnel.

\section{Measurement of glucose and beta-ketones and adipose tissue isolation}

Glucose and beta-ketone levels in the blood were measured directly before and $6 \mathrm{~h}$ after LPS application. Therefore, a tail vein was punctured and a small blood drop taken with the respective test strips (FreeStyle Precision, Abbott). $24 \mathrm{~h}$ after LPS treatment, mice were sacrificed and inguinal white adipose tissue (WAT) and the interscapular brown adipose tissue (BAT) were harvested and weighed.

\section{Histopathology}

Organs (lung, liver, spleen and kidney) were harvested $16 \mathrm{~h}$ after LPS injection and transferred immediately into $4 \%$ buffered formaldehyde for fixation. Lungs were inflated with $4 \%$ buffered formaldehyde prior to fixation. After $48 \mathrm{~h}$ at $4{ }^{\circ} \mathrm{C}$ in formaldehyde, organs were washed with and stored in $70 \%$ ethanol before dehydrating, embedding in paraffin and cutting $2 \mu \mathrm{m}$ sections. Sections were stained with haematoxylin and eosin (H\&E) and analysed by a certified pathologist in a blinded fashion. The lungs were scored for two pathological alterations, which characterize interstitial pneumonia: (1) alveolar septal thickening caused by infiltration of inflammatory cells, fibrin exudation and interstitial oedema and (2) oedema affecting the interstitium except the alveolar walls. Both changes were graded from 0 to $3(0=$ no alterations, $1=$ mild, $2=$ moderate, $3=$ severe 
alterations). The two scores were summed up and the total interstitial pneumonia score is given in the figure.

\section{Immunohistochemistry}

For immunohistochemical staining, sections were deparaffinized, rehydrated and endogenous peroxidase activity was blocked with $2 \% \mathrm{H}_{2} \mathrm{O}_{2}$. Antigen retrieval was performed with $20 \mu \mathrm{g} / \mathrm{ml}$ proteinase $\mathrm{K}$ (for $\mathrm{F} 4 / 80$ staining), $0.01 \%$ pronase (for neutrophil staining with NIMP-R14) or citrate-based antigen unmasking solution $(\mathrm{pH} 6$, Vector labs; for cleaved caspase-3 staining), followed by several blocking steps. Sections were incubated overnight at $4{ }^{\circ} \mathrm{C}$ (anti-cleaved caspase- 3 antibody or anti-neutrophil antibody NIMP-R14) or for $1 \mathrm{~h}$ at room temperature (anti-F4/80 antibody). Antibodies and dilutions are given in Supplementary Table 1. After incubation with the respective secondary antibody, stainings were visualized with the Vectastain $\mathrm{ABC}$ kit and $\mathrm{DAB}$ substrate (Vector labs) and sections were counterstained with haematoxylin. For quantifications, 5 pictures per section were taken with the upright research microscope Axio Imager Z.2 (Carl Zeiss) with 20-fold magnification and positive signals from each picture were counted with the Fiji software (http://fiji.sc) and are shown as mean/section.

\section{Luminex bead-based multiplex assay}

Systemic cytokine levels were measured with the Luminex bead-based multiplex assay (Thermo Fisher Scientific). Blood was collected via the retrobulbar venous plexus and either serum or plasma was separated, depending on additional analysis needed from the samples. ProcartaPlex Simplex Kits from the cytokines of our interest were used and samples processed according to the manufacturer's instructions. Analysis was performed with the Luminex Bio-Plex 200 system and the Bio-Plex Manager software (Bio-Rad).

\section{Isolation and stimulation of bone marrow-derived macrophages (BMDMs)}

BMDMs were isolated and grown as described [15]. Briefly, bone marrow was flushed out from both hind legs and BMDMs were grown and differentiated at $37^{\circ} \mathrm{C}$ and with $5 \% \mathrm{CO}_{2}$ for 7 days in BMDM growth medium (high glucose DMEM, supplemented with $10 \%$ FCS, $100 \mathrm{U} / \mathrm{ml}$ penicillin $/ 100 \mu \mathrm{g} / \mathrm{ml}$ streptomycin, $2 \mathrm{mM}$ L-glutamine, $50 \mu \mathrm{M} \beta$-mercaptoethanol and 15\% L929 cell-conditioned medium). On day $7,1 \times 10^{6}$ cells/well were seeded into six-well cell culture plates and treated on day 8 in $1.2 \mathrm{ml}$ Opti-MEM reduced serum medium (Gibco)/well as follows: unstimulated (medium only), mock transfection
[FuGene $^{\circledast} \quad$ (Promega) $\left.0.25 \% \quad(\mathrm{v} / \mathrm{v})\right], \quad$ LPS transfection [FuGene ${ }^{\circledR}$ (Promega) $0.25 \%$ (v/v) and $2 \mu \mathrm{g} / \mathrm{ml}$ LPS] or LPS (LPS $100 \mathrm{ng} / \mathrm{ml}$ ). For LPS + ATP, $3 \mathrm{mM}$ ATP (Sigma) was added $16 \mathrm{~h}$ after LPS (LPS $100 \mathrm{ng} / \mathrm{ml}$ ) treatment for $2 \mathrm{~h}$.

For the pharmacological inhibition of TYK2, cells were treated with the indicated dose of the allosteric TYK2 inhibitor BMS-986165 (MedChemExpress) or with DMSO as control $(0.01 \% \mathrm{v} / \mathrm{v})$ together with LPS $(100 \mathrm{ng} / \mathrm{ml})$ in growth medium for $18 \mathrm{~h}$.

\section{Culture, differentiation and stimulation of U937 cells}

U937 cells were kindly provided by Thomas Decker (Max Perutz Labs, Vienna BioCenter, Vienna, Austria) and originally obtained from ATCC (ATCC ${ }^{\circledR}$ CRL-1593.2 ${ }^{\mathrm{TM}}$ ). Cells were tested negative for mycoplasma and were cultured in U937 growth medium (RPMI-1640 medium, supplemented with $10 \%$ FCS and $100 \mathrm{U} / \mathrm{ml}$ penicillin/100 $\mu \mathrm{g} /$ $\mathrm{ml}$ streptomycin), at $37^{\circ} \mathrm{C}$ and $5 \% \quad \mathrm{CO}_{2}$. Prior to the experiments, U937 cells were differentiated into macrophages as described [21] with minor modifications: cells were treated with $10 \mathrm{nM}$ PMA $\left(1 \times 10^{6}\right.$ cells/well of sixwell cell culture plates) for $48 \mathrm{~h}$, washed with pre-warmed PBS and kept in growth medium for another $24 \mathrm{~h}$. Stimulations were performed as described for BMDMs.

\section{Cell lysis and trichloroacetic acid (TCA) precipitation}

Cells were lysed in $150 \mu \mathrm{l}$ lysis buffer containing $50 \mathrm{mM}$ Tris/HCl pH 8, 0.5\% NP-40 (Igepal CA-630), 10\% (v/v) glycerol, $0.1 \mathrm{mM}$ EDTA pH 8, $150 \mathrm{mM}$ sodium chloride, $25 \mathrm{mM}$ sodium fluoride, $2 \mathrm{mM}$ DTT, $0.2 \mathrm{mM}$ sodium orthovanadate, $1 \mathrm{mM}$ PMSF, $10 \mu \mathrm{g} / \mathrm{ml}$ leupeptin, $10 \mu \mathrm{g} / \mathrm{ml}$ aprotinin, $1 \mu \mathrm{g} / \mathrm{ml}$ pepstatin. U937 cells were directly lysed in $100 \mu \mathrm{l} \mathrm{1x}$ Laemmli sample buffer and immediately incubated at $99{ }^{\circ} \mathrm{C}$ for $10 \mathrm{~min}$ (shaking at $1400 \mathrm{rpm}$ ).

Cell culture supernatant was collected for TCA precipitation: $900 \mu \mathrm{l}$ were mixed with $13.5 \mu \mathrm{l} 10 \%$ (w/v) sodium deoxycholate monohydrate and $300 \mu$ ice-cold $6.1 \mathrm{M}$ TCA and incubated for $1 \mathrm{~h}$ on ice. Samples were centrifuged for $15 \mathrm{~min}$ at $20,000 \times g$ at $4{ }^{\circ} \mathrm{C}$ and pellets were washed 3 times with ice-cold acetone. After the last washing step, pellets were air-dried for $10 \mathrm{~min}$ on ice, dissolved in $20 \mu \mathrm{l} 0.2 \mathrm{M}$ $\mathrm{NaOH}$ and incubated for another $10 \mathrm{~min}$ on ice. The samples were vortexed, $30 \mu \mathrm{l}$ of ultrapure water was added and again incubated for $10 \mathrm{~min}$ on ice. In all, $50 \mu \mathrm{l}$ of $2 \mathrm{x}$ Laemmli sample buffer was added to each sample.

\section{Organ homogenization and western blot}

Organs were harvested $16 \mathrm{~h}$ after LPS injection, shock frozen in liquid nitrogen and stored at $-80{ }^{\circ} \mathrm{C}$. For protein 
extraction, organs were homogenized with the $1600 \mathrm{MiniG}$ tissue homogenizer at $1500 \mathrm{rpm}$ for $30 \mathrm{~s}$ (Spex SamplePrep) in lysis buffer (as described above for BMDMs). Cell and organ lysates were centrifuged to remove cell debris $(16,000 \times g)$. Lysates were mixed with $2 x$ Laemmli sample buffer and boiled for $5 \mathrm{~min}$ at $95{ }^{\circ} \mathrm{C}$. In all, $15 \mu \mathrm{g}$ of total cell lysate from spleens, 5-10 $\mu \mathrm{g}$ from BMDM lysates, $10 \mu \mathrm{l}$ from U937 lysates or $15 \mu$ of TCA-precipitated cell culture supernatants were loaded per lane. Proteins were separated by SDS-PAGE and blotted onto nitrocellulose (for the detection of GSDMD, CASP4 and CASP5) or PVDF membranes. Membranes were probed with the primary antibodies overnight at $4{ }^{\circ} \mathrm{C}$. Incubation with the secondary antibodies was for $1 \mathrm{~h}$ at room temperature. The detection of chemiluminescence was performed by incubating the membrane with Clarity Western ECL substrate (Bio-Rad) and using ChemiDoc Touch Imaging System (Bio-Rad). Antibodies and dilutions are given in Supplementary Table 1.

\section{RNA extraction and RT-qPCR}

For total RNA extraction, organs were homogenized (as described above) in peqGOLD TriFast reagent (Peqlab) and cDNA was generated with the iScript cDNA Synthesis Kit (Bio-Rad). qPCR for $I l l b$ was performed on the Stratagene MX3000 instrument (Agilent Technology), all others were performed on the CFX Touch Real-Time PCR Detection System (Bio-Rad). Ube2d2 was used as housekeeping gene. See Supplementary Table 1 for assays, primers and probes.

\section{Propidium iodide and Hoechst staining}

Propidium iodide (PI) and Hoechst (ThermoFisher) were mixed in PBS to concentrations of $2 \mu \mathrm{g} / \mathrm{ml}$ (PI) and $5 \mu \mathrm{g} / \mathrm{ml}$ (Hoechst). BMDMs were incubated with the staining solution for $10 \mathrm{~min}$ at $37^{\circ} \mathrm{C}$ in the dark and washed twice with PBS. For quantification, pictures were taken with the inverted microscope Axio Observer Z1 (Carl Zeiss) from three different regions. Positive signals for PI and Hoechst were counted with the Fiji software (http://fiji.sc). Results are shown as \% PI-positive cells (out of Hoechst-positive cells), mean values from three pictures are given.

\section{Lactate dehydrogenase measurement}

Lactate dehydrogenase (LDH) measurement in cell culture supernatants was performed as described [22, 23]. In brief, $25 \mu \mathrm{l}$ sample was mixed with $25 \mu \mathrm{l}$ assay substrate $(12 \mathrm{mg} / \mathrm{ml}$ lactate, $0.66 \mathrm{mg} / \mathrm{ml} \mathrm{INT,} 4.5 \mathrm{U} / \mathrm{ml}$ diaphorase, $0.01 \% \mathrm{BSA}$, $0.4 \%$ sucrose, $1 \mathrm{mg} / \mathrm{ml} \mathrm{NAD}^{+}$) and incubated at room temperature for $15 \mathrm{~min}$. In all, $25 \mu \mathrm{l}$ stop solution (1 M acetic acid) was added and the read-out performed at $490 \mathrm{~nm}$ (wavelength correction at $570 \mathrm{~nm}$ ) on the Epoch Microplate Spectrophotometer (BioTek). Results are presented as \% LDH release and mock transfected BMDMs served as control.

\section{Reagents}

For detailed information about chemicals, antibodies, assays and primers used in this study, see Supplementary Table 1.

\section{Statistical analysis}

Log-rank (Mantel-Cox) test (Fig. 1a), Kruskal-Wallis test (Fig. 1g), unpaired two-tailed $t$-test with Welch correction (Figs. 4a and 6a, b), One-way ANOVA followed by Tukey's multiple comparisons test (Figs. 4j and 5e), BrownForsythe and Welch ANOVA followed by Dunett's multiple comparison test (Fig. 2a-c), or Two-way ANOVA followed by Bonferroni's (Fig. 6e) or Tukey's (Figs. 1b, h, i, $4 \mathrm{i}, 5 \mathrm{~d}$ and $6 \mathrm{f}$ ) multiple comparisons test. PBS and LPS groups were analysed separately (one-way ANOVA followed by Tukey's multiple comparisons test) when data did not meet the assumption of equal variance (Figs. 1d-e and $3 \mathrm{a}-\mathrm{d})$. Statistical analysis was performed using GraphPad Prism 8 for Mac (GraphPad Software). Sample size and number of experiments are given in the figure legends. Significance was defined as follows: $* p \leq 0.05$, $* * p \leq 0.01, * * * p \leq 0.001, * * * * p \leq 0.0001$.

\section{Results}

\section{TYK2 aggravates LPS-induced endotoxin shock, thrombocytopenia and histopathological changes in liver and lung}

To test whether kinase-independent functions of TYK2 contribute to LPS-induced pathogenesis, mice expressing kinase inactive TYK2 (Tyk2 $\left.2^{K 923 E}\right)$, Ty $k 2^{-/-}$and wild-type (WT) mice were challenged with high-dose LPS and survival was monitored over time. $T y k 2^{K 923 E}$ and $T y k 2^{-/-}$mice showed strongly improved survival compared to WT mice (Fig. 1a). Weight-loss (Fig. 1b) and hypothermia (Supplementary Fig. 1a) were similar to $W T$ mice until $24 \mathrm{~h}$ after LPS injection, the time point when the majority of WT mice reached humane endpoint criteria. WT and Tyk2-mutant mice also showed a comparable drop in glucose and increase in beta-ketone levels (Supplementary Fig. 1b, c), suggesting that TYK2 does not affect the ability to metabolize glucose and to gain energy from stored fat. Mass of white and brown adipose tissue (WAT and BAT) after LPS injection was similar between mice of all genotypes after LPS injection (Supplementary Fig. 1d, e), indicating that 
a

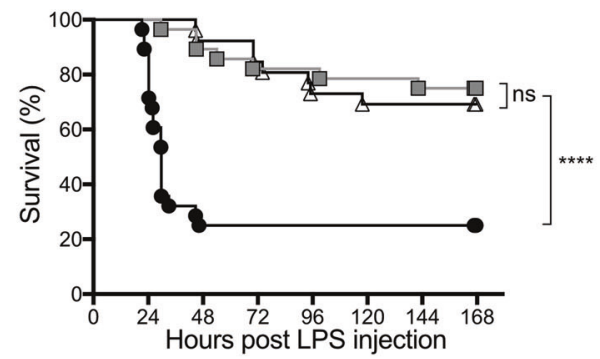

C

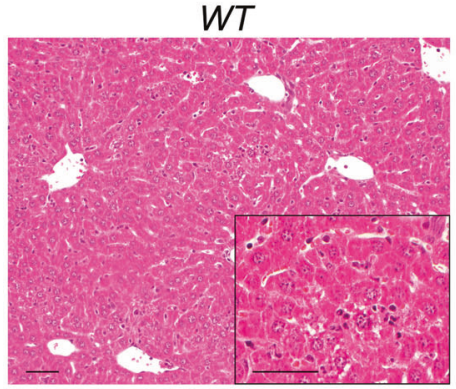

b

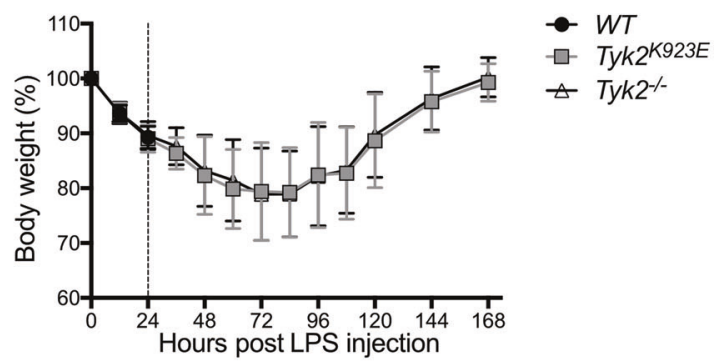

Tyk $2^{K 923 E}$

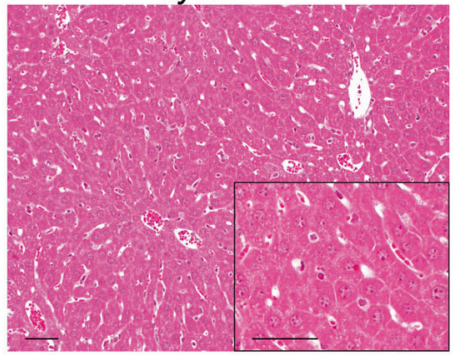

Tyk2--

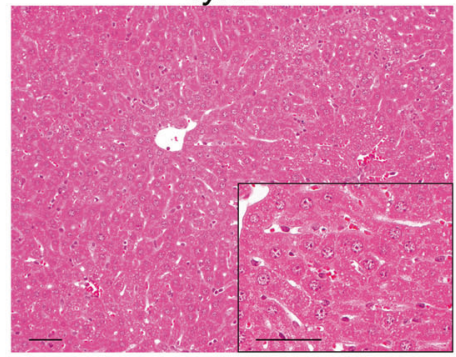

Liver (16 hours LPS), H\&E staining, scalebar $50 \mu \mathrm{m}, 200 x$, inset $400 x$

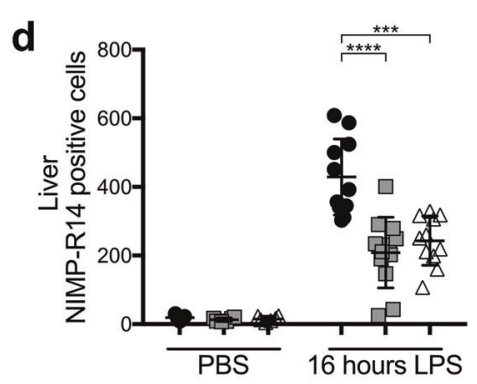

f

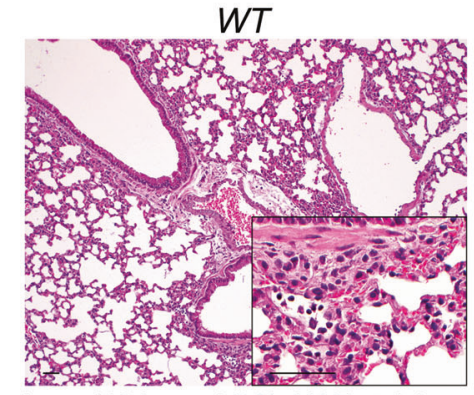

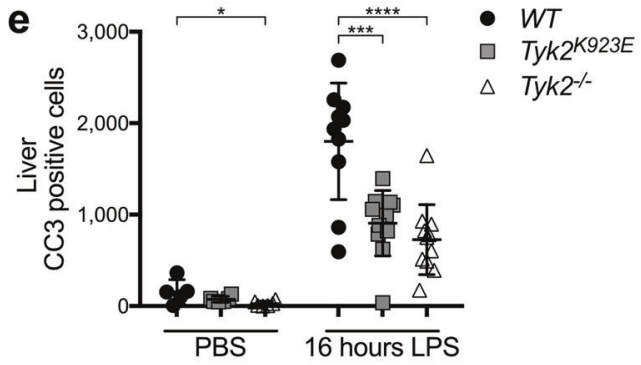

Tyk2 $2^{K 923 E}$

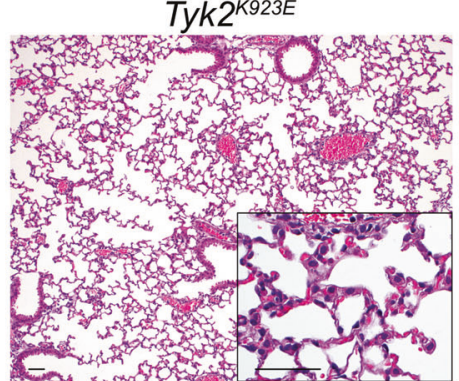

Tyk2-1-

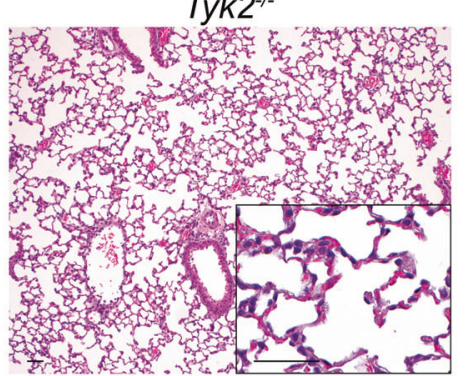

Lung (16 hours LPS), H\&E staining, scalebar $50 \mu \mathrm{m}, 100 x$, inset $400 x$

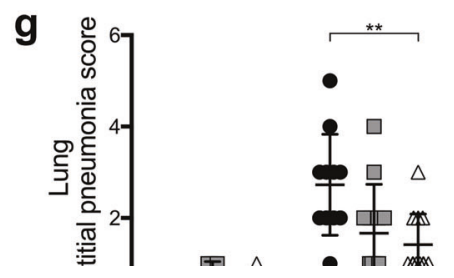

h

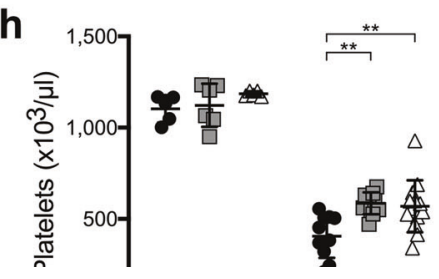

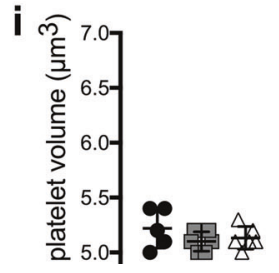

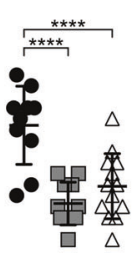

- $W T$

$T y k 2$ K9

$\triangle T y k 2^{-1-}$ mice do not differ in regard to the use of WAT and BAT to produce energy and heat. LPS-induced lethality occurs through multiple organ failure [24-26] but only a few reports exist on organ pathologies induced by high-dose
LPS. The most prominent finding in liver sections of $W T$ mice was diffuse infiltration of neutrophils into the sinusoids, which was substantially decreased in $T y k 2^{K 923 E}$ and $\mathrm{Tyk}^{-/-}$mice (Fig. 1c). This was confirmed by 
Fig. 1 TYK2 aggravates LPS-induced endotoxin shock, thrombocytopenia and histopathological changes in liver and lung. $W T, T y k 2^{K 923 E}$ and $T y k 2^{-/-}$mice were injected i.p. with $50 \mathrm{mg} / \mathrm{kg}$ LPS and monitored for 7 days with respect to $\mathbf{a}$ survival and $\mathbf{b}$ body weight. Data are pooled from two independent experiments $(n=26-28 / \mathrm{gen}-$ otype) and represented as mean $\pm \mathrm{SD}$. The vertical dotted line in b indicates the time point when the majority of WT mice reached humane endpoint criteria. c-g $W T, T y k 2^{K 923 E}$ and $T y k 2^{-/-}$mice were injected i.p. with $50 \mathrm{mg} / \mathrm{kg}$ LPS or PBS as control and $16 \mathrm{~h}$ later, $\mathbf{c}-\mathbf{e}$ liver and $\mathbf{f}$, $\mathbf{g}$ lung were taken for histopathological analysis $(n=5-6$ for PBS and $n=10-12 /$ genotype for LPS samples). Representative pictures of H\&E stained $\mathbf{c}$ liver and $\mathbf{f}$ lung sections. $\mathbf{d}$ Quantification of NIMP-R14 staining for infiltrating monocytes and neutrophils, representative pictures are shown in Supplementary Fig. 2a. e Quantification of cells positive for cleaved caspase-3 (CC3), representative pictures are shown in Supplementary Fig. 2b. g Interstitial pneumonia scores from lung sections. h, i Blood was taken $16 \mathrm{~h}$ after LPS injection and $\mathbf{h}$ the number of platelets and $\mathbf{i}$ the mean platelet volume was determined with a VetABC blood analyzer $(n=5-6$ for PBS and $n=10-13$ /genotype for LPS samples). d, e, $\mathbf{g}-\mathbf{i}$ Data are pooled from two independent experiments, horizontal lines and error bars represent mean \pm SD. $* p \leq 0.05, * * p \leq 0.01, * * * p \leq 0.001$, **** $p \leq 0.0001$.

immunohistochemical staining for neutrophils and inflammatory monocytes (NIMP-R14; Fig. 1d and Supplementary Fig. 2a). Tyk2-mutant mice had less cells positive for cleaved caspase-3 (CC3; Fig. 1e and Supplementary Fig. 2b), indicating a decrease in apoptosis in the absence of kinase-active TYK2, but no differences in the number of resident macrophages (i.e. $\mathrm{F} 4 / 80^{+}$cells; Supplementary Fig. 2c, d). In the lung, the interstitial pneumonia score was lower in Tyk2-mutant than in WT mice (Fig. 1f, g). Disseminated intravascular coagulation is a common feature of endotoxin shock, leading to thrombi formation, platelet consumption and subsequent organ damage [27]. The LPSinduced decrease in platelet numbers and the increase in mean platelet volume, which is indicative for an increase in the frequency of platelet precursors, was less pronounced in Tyk2-mutant mice (Fig. 1h, i). LPS treatment did not result in histopathological alterations in kidneys (data not shown).

Taken together, these data suggest that the absence or enzymatic inactivation of TYK2 protects from liver and lung pathology and reduces thrombocytopenia in response to high-dose LPS challenge.

\section{TYK2 promotes the production of pro-inflammatory cytokines during endotoxemia}

We next assessed systemic cytokine levels in $W T, T y k 2^{K 923 E}$ and $T y k 2^{-1-}$ mice at 2, 6 and $16 \mathrm{~h}$ after LPS injection. IL-6, $\mathrm{TNF} \alpha$ and IL-1 $\beta$ levels were comparable in mice of all genotypes at $2 \mathrm{~h}$ after LPS challenge (Fig. 2a), confirming that immediate early pro-inflammatory responses do not depend on TYK2 [13, 14]. Against our expectations, IL-6, TNF $\alpha$, IL- $1 \beta$ and IL-18, which was first detectable at $6 \mathrm{~h}$ after treatment, were strongly reduced in $T y k 2$-mutant mice at 6 and $16 \mathrm{~h}$ after LPS treatment (Fig. 2b, c). In line with reports on $T y k 2^{-/-}$mice [12, 14], Tyk $2^{K 923 E}$ mice failed to produce IFN $\gamma$ and had strongly reduced systemic IL-27 levels (Supplementary Fig. 3a, b). Moreover, $T y k 2^{K 923 E}$ and $T y k 2^{-/-}$mice failed to produce IL-17A (Supplementary Fig. 3a, b), extending the reports on the importance of TYK2 for IL-17A production [2, 3, 28-32] to LPS-induced endotoxemia.

\section{TYK2 does not impact on II1b and II18 mRNA levels but facilitates transcriptional upregulation of Casp11}

Ill8 mRNA is constitutively expressed in myeloid and epithelial cells, whereas $I l 1 b$ is transcriptionally regulated [33]. $I l 1 b$ mRNA was strongly upregulated by LPS treatment and did not grossly differ between $W T, T y k 2^{K 923 E}$ and $T y k 2^{-1-}$ mice in spleen (Fig. 3a), lung and liver (Supplementary Fig. 4a, b). Ill8 mRNA levels did not change upon LPS treatment and were only modestly lower in Tyk2mutant mice $6 \mathrm{~h}$ after LPS treatment (Fig. $3 \mathrm{~b}$ and Supplementary Fig. 4c). In contrast to other cytokines (e.g. IL-6, TNF $\alpha$, IL-27 and IL-17A), IL-1 $\beta$ and IL-18 are produced as precursors that require proteolytic processing by CASP1, which is activated by the formation of an inflammasome, and release through pyroptosis [33, 34]. Caspl mRNA levels in spleen and liver modestly changed upon LPS treatment and were lower in $T y k 2$-mutant mice before and/ or after LPS treatment (Fig. 3c and Supplementary Fig. 4d). However, this did not translate into gross differences in CASP1 protein levels (Fig. 3e). CASP11 is the central component of the non-canonical inflammasome, senses intracellular LPS and drives LPS-induced lethality in vivo [35-39]. Caspl1 mRNA and protein were strongly induced by LPS in spleen and liver of WT mice, which was profoundly decreased in $T y k 2^{K 923 E}$ and $T y k 2^{-/-}$mice (Fig. 3d, e and Supplementary Fig. 4e).

Collectively, these data show that TYK2 is essential for the transcriptional induction of Casp11 but dispensable for the upregulation of $I l l b$ mRNA and only modestly affects the expression of $I l 18$.

\section{TYK2 and its kinase activity is required for the induction of CASP11 and the release of mature IL-1 $\beta$ and IL-18 in response to intracellular LPS}

Monocytes and macrophages are among the main producers of IL-1 $\beta$ and IL-18 [40-42]. To test whether TYK2 in these cells contributes to the production of IL- $1 \beta$ and IL-18 during LPS-induced endotoxemia, we made use of mice that lack TYK2 specifically in monocytes, macrophages and granulocytes $\left(T y k 2^{f / f f} \times\right.$ LysMCre mice, herein referred to as $\left.T y k 2^{\Delta L y s M}\right)$. IL-1 $\beta$ and IL-18 levels were drastically reduced 

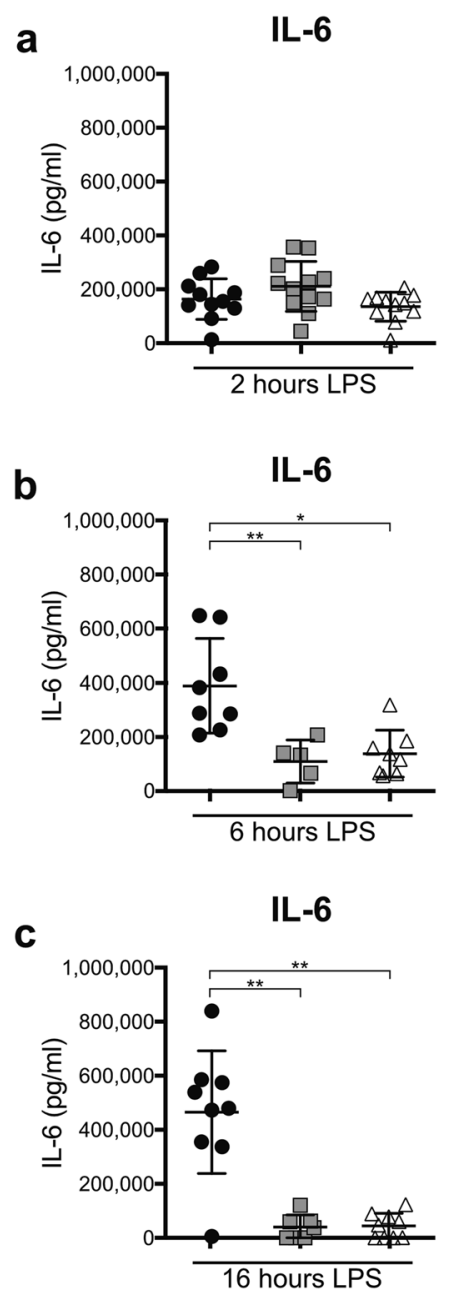

Fig. 2 TYK2 promotes the production of pro-inflammatory cytokines during endotoxemia. $W T, T y k 2^{K 923 E}$ and $T y k 2^{-/-}$mice were injected i.p. with $50 \mathrm{mg} / \mathrm{kg}$ LPS and plasma levels of IL-6, TNF $\alpha$, IL$1 \beta$ and IL-18 were measured with Luminex bead-based multiplex

in $T y k 2^{\Delta L y s M}$ mice compared to littermate controls, whereas IL-6 and TNF $\alpha$ levels did not significantly differ between mice of the two genotypes (Fig. 4a).

To test the hypothesis that TYK2 is required for noncanonical inflammasome activation, we analysed levels of CASP11, CASP1 and processing and release of IL- $1 \beta$ and IL-18 in BMDMs from WT, Tyk2 $2^{K 923 E}$ and $T y k 2^{-/-}$mice in response to intracellular LPS. In addition, we treated cells with extracellular LPS with or without subsequent treatment with ATP, which activates the canonical NLRP3 inflammasome independently of CASP11. CASP11 was strongly upregulated in WT but not in $T y k 2^{K 923 E}$ and $T y k 2^{-1-}$ BMDMs upon LPS transfection (Fig. 4b) or treatment with extracellular LPS +/-ATP (Fig. 4c). CASP1 protein levels neither changed upon LPS treatment nor differed between WT and Tyk2-mutant BMDMs (Fig. 4b, c). Consistent with our previous study [15], pro-IL-1 $\beta$ levels were higher in $T y k 2^{K 923 E}$ and $T y k 2^{-/-}$BMDMs, irrespective of whether LPS was delivered intra- or extracellularly (Fig. 4b, c). Pro-
IL-1 $\beta$

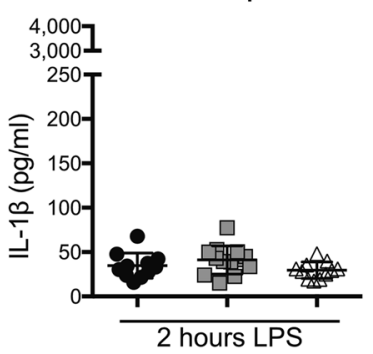

- WT

口 Tyk2K923E

$\triangle T y k 2^{-/-}$
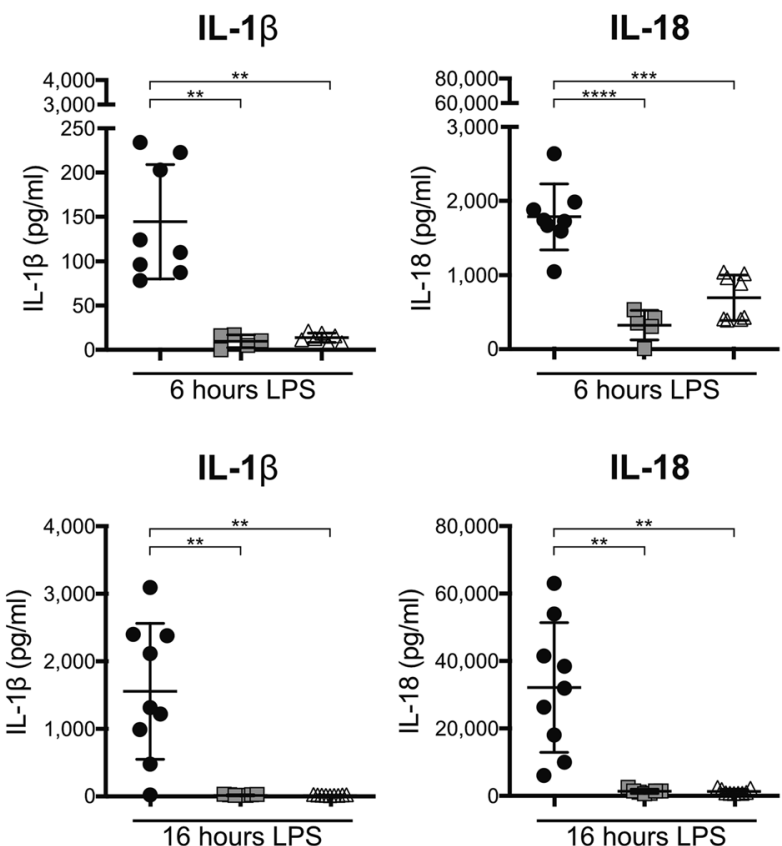

assay at $\mathbf{a} 2 \mathrm{~h}$ ( $n=11-13 /$ genotype), b $6 \mathrm{~h}(n=5-11 /$ genotype $)$ and $\mathbf{c}$ $16 \mathrm{~h}(n=7-11 /$ genotype). Data are pooled from two independent experiments, horizontal lines and error bars represent mean \pm SD. $* p \leq$ $0.05, * * p \leq 0.01, * * * p \leq 0.001, * * * * p \leq 0.0001$.

IL-18 was comparably upregulated in BMDMs of all genotypes (Fig. $4 \mathrm{~b}, \mathrm{c}$ ). $T y k 2^{K 923 E}$ and $T y k 2^{-/-}$BMDMs did not release IL-18 and showed reduced levels of IL-1 $\beta$ in supernatants upon LPS transfection, despite the strong increase of intracellular pro-IL-1 $\beta$ (Fig. 4d). In contrast to previous reports [35, 43], we did not detect cleaved CASP1 in cell culture supernatants of LPS-transfected cells (Fig. 4d). Upon treatment with extracellular LPS + ATP, IL-1 $\beta$ was increased in supernatants of $T y k 2$-mutant BMDMs (Fig. 4e), which is in line with our previous study [15]. Although intracellular pro-IL-18 was not increased in $T y k 2^{K 923 E}$ and $T y k 2^{-/-}$BMDMs, we observed increased release of IL-18 and cleaved CASP1 (Fig. 4e), indicating enhanced NLRP3 inflammasome activity.

CASP11 does not directly process pro-IL- $1 \beta$ and pro-IL18 but induces pyroptosis through the cleavage of gasdermin D (GSDMD) [44-46], which results in secondary activation of CASP1 through the NLRP3 inflammasome [37, 47]. LPS transfection induced considerably higher 

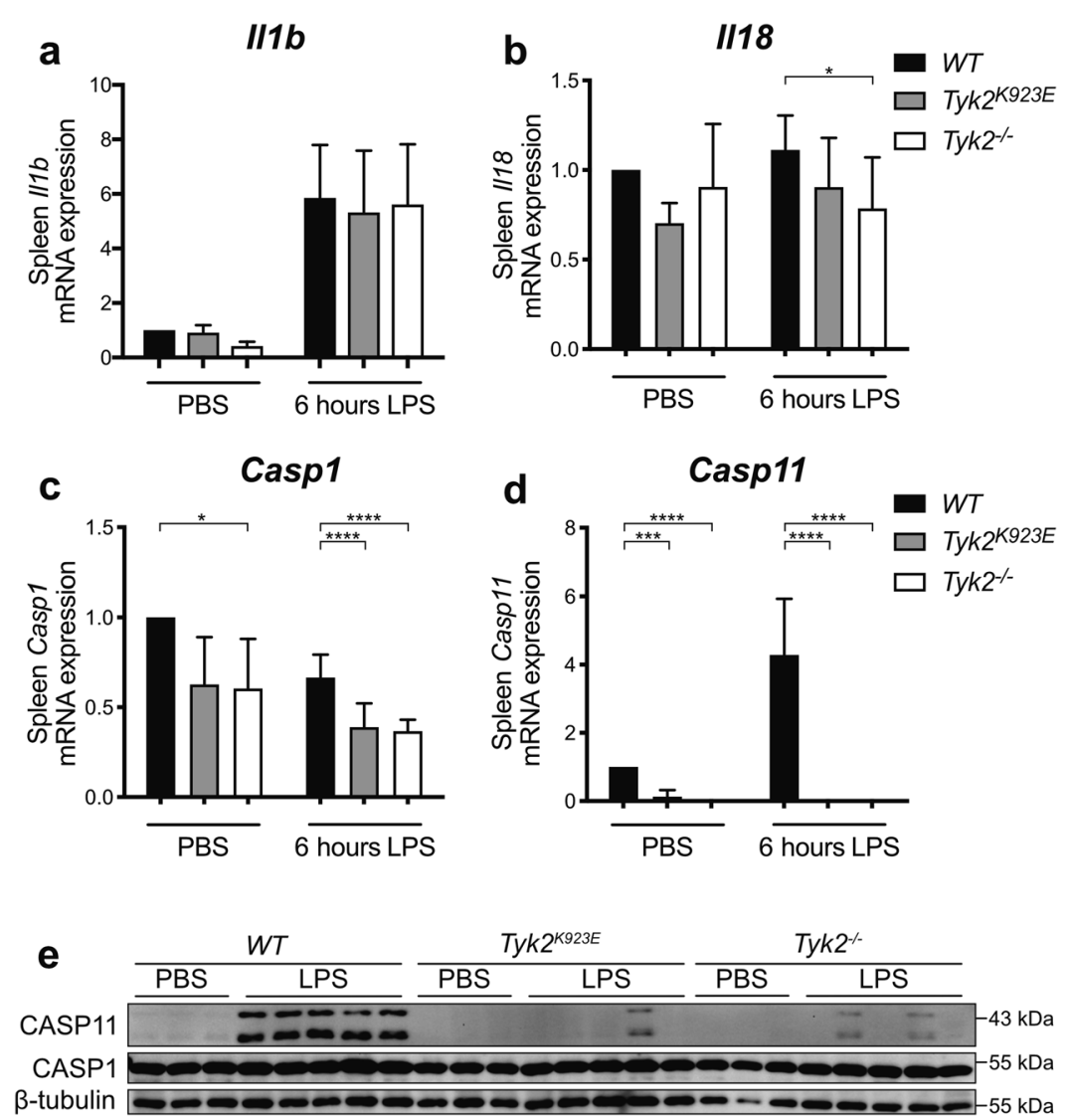

Fig. 3 TYK2 does not impact on $I l 1 b$ and $I l 18$ mRNA levels but facilitates transcriptional upregulation of Casp11. WT, Tyk $2^{K 923 E}$ and $T y k 2^{-/-}$mice were injected i.p. with $50 \mathrm{mg} / \mathrm{kg}$ LPS or PBS as control and a-d $6 \mathrm{~h}$ later spleen was harvested and mRNA levels of a $I l 1 b$, b $I l 18$, c Caspl and d Caspl1 were measured by RT-qPCR ( $n=$ $2-5$ for PBS and $n=8-9 /$ genotype for LPS samples). Results are shown as relative expression compared to WT mice injected with PBS. Data are pooled from two independent experiments and represented as

GSDMD cleavage in $W T$ than in Tyk2-mutant BMDMs (Fig. 4f), whereas the opposite was observed in response to extracellular LPS + ATP (Fig. 4g). NLRP3 was upregulated upon treatment with intra- or extracellular LPS and levels did not grossly differ between $W T$ and Tyk2-mutant BMDMs (Fig. 4f, g), supporting previous studies indicating that IFN $\alpha / \beta$ does not suppress LPS-induced upregulation of NLRP3 but enhances its activity [48, 49].

To further substantiate that non-canonical inflammasome activation and pyroptosis is impaired in the absence of enzymatically active TYK2, we analysed cell death by staining cells with PI, which only stains cells with a disrupted cell membrane. The percentage of PI-positive cells was significantly reduced in LPS-transfected $T y k 2^{K 923 E}$ and $T y k 2^{-1-}$ BMDMs (Fig. 4h, i). Consistently, we detected lower levels of lactate dehydrogenase (LDH), a cytosolic enzyme that is only released upon disruption of the plasma membrane, in the supernatant of transfected $T y k 2^{K 923 E}$ and Tyk $2^{-/-}$BMDMs (Fig. 4j). mean \pm SD. $* p \leq 0.05, * * p \leq 0.01, * * * p \leq 0.001, * * * * p \leq 0.0001$. e 16 $\mathrm{h}$ after LPS treatment CASP11 and CASP1 protein levels were determined in spleen lysates by western blot $(n=5 /$ genotype). In all, $15 \mu \mathrm{g}$ of total cell lysate was loaded per lane and $\beta$-tubulin was used as loading control. Molecular weights of the pre-stained protein marker bands are indicated. Data are representative of two independent experiments.

Collectively, these data show that TYK2 functions upstream of the induction of CASP11, the cleavage of GSDMD and the release of mature IL- $1 \beta$ and IL-18 in response to intracellular LPS. Furthermore, our data indicate that TYK2 has opposing effects on the release of biologically active IL-1 $\beta$ and IL-18 in response to noncanonical and canonical inflammasome activation.

\section{Intact type I IFN signalling is required for the induction of CASP11 and the release of mature IL-1 $\beta$ and IL-18 in response to intracellular LPS}

CASP11 can be induced by IFN $\beta$ and IFN $\gamma$ [37, 50-52]. Macrophages lacking a functional type I IFN receptor (Ifnarl $^{-/-}$) fail to induce CASP11 in response to infection with Gram-negative bacteria or treatment with extracellular LPS [51], suggesting that the impaired induction of CASP11 in $T y k 2^{K 923 E}$ and $T y k 2^{-/-}$BMDMs reflects their defects in type I IFN signalling. To confirm these finding in 

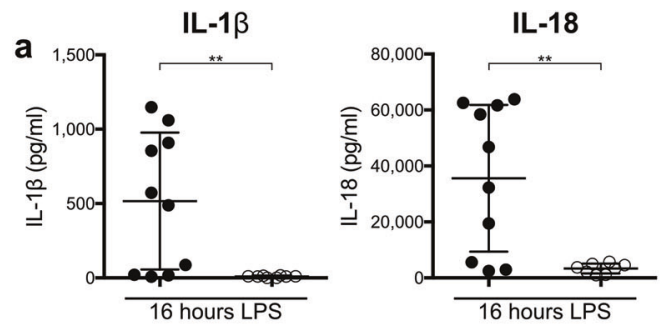

b

Cell lysate

$\underline{\text { Unstim. }} \begin{gathered}\text { Mock } \\ \text { transfection transfection }\end{gathered}$

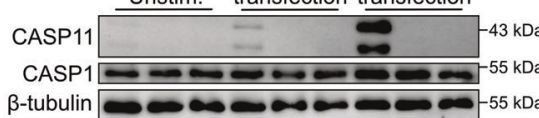

$\beta$-tubulin

pro-IL-1 $1 \beta$

pro-IL-18

panERK

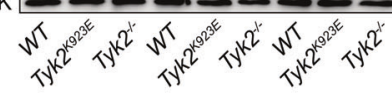

d Cell culture supernatant

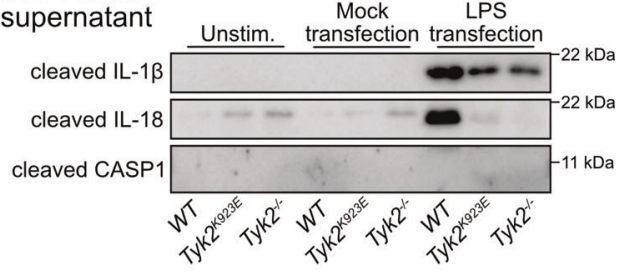

f

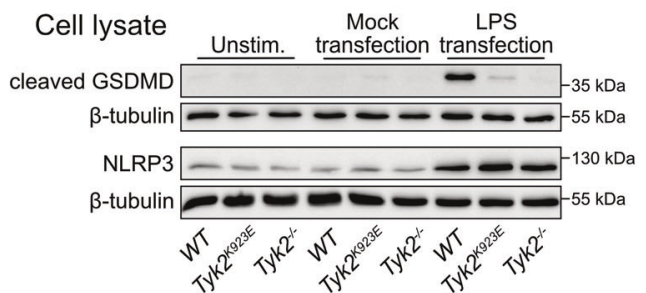

h

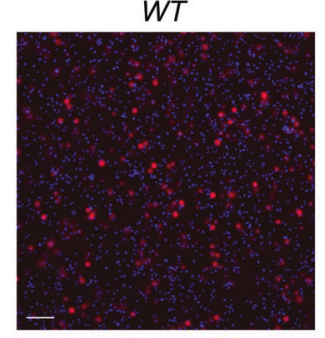

Scalebar $100 \mu \mathrm{m}, 100 \mathrm{x}$

red: propidium iodide; blue: Hoechst

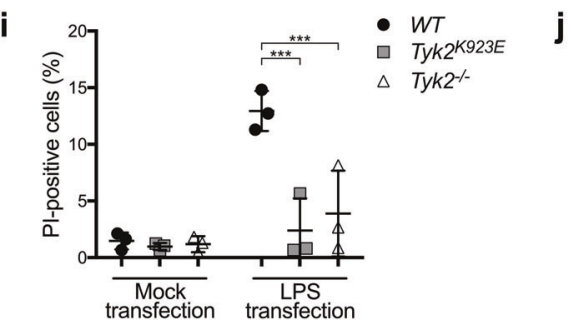

Tyk $2^{K 923 E}$

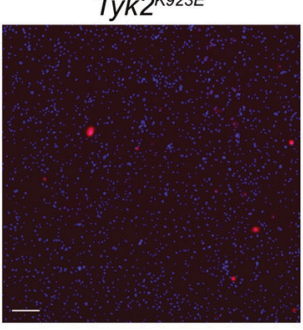

g Cell lysate

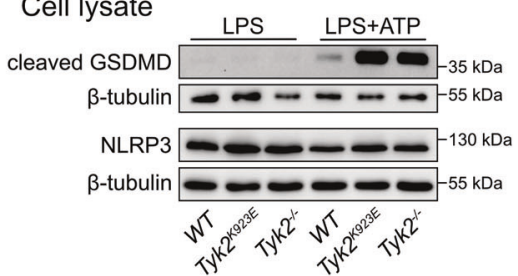

Cell culture supernatant
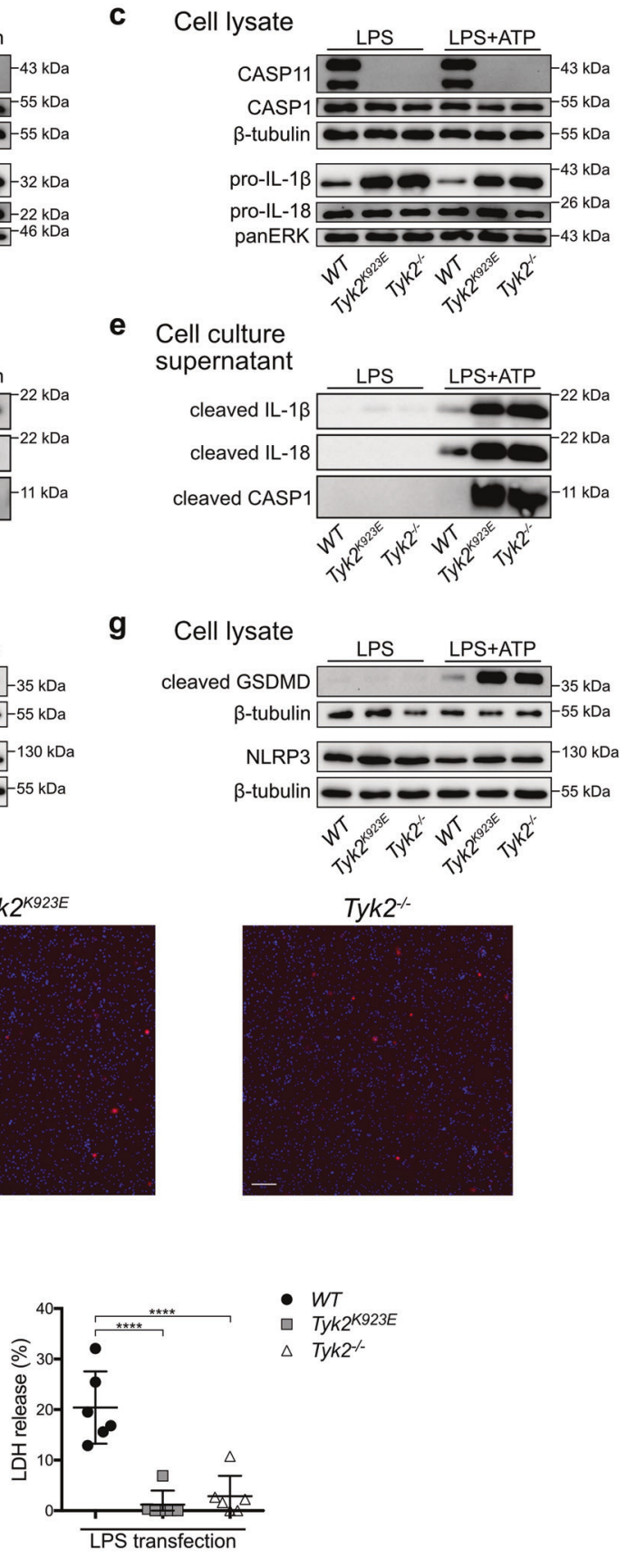

the context of LPS transfection, we analysed CASP11, CASP1, cleaved GSDMD and NLRP3 levels, IL-1 $\beta$ and IL18 processing and release and cell death in Ifnarl $^{-1-}$
BMDMs. To formally exclude effects of IFN $\gamma$ in this experimental setting, we included BMDMs from mice that lack a functional IFN $\gamma$ receptor $\left(\right.$ Ifngrl $\left.{ }^{-/-}\right)$. Similar to 
Fig. 4 TYK2 and its kinase activity is required for the induction of CASP11 and the release of mature IL-1 $\beta$ and IL-18 in response to intracellular LPS. a Mice lacking TYK2 in myeloid cells $\left(T y k 2^{\Delta L y s M}\right)$ and littermate controls $\left(T y k 2^{f / f l}\right)$ were injected i.p. with $50 \mathrm{mg} / \mathrm{kg}$ LPS and levels of IL-1 $\beta$, IL-18, IL- 6 and TNF $\alpha$ were measured in the plasma with Luminex bead-based multiplex assay after $16 \mathrm{~h}$ of LPS treatment ( $n=8-10 /$ genotype). Data are pooled from two independent experiments. b-j BMDMs from $W T, T y k 2^{K 923 E}$ and $T y k 2^{-/-}$mice were $\mathbf{b}, \mathbf{d}, \mathbf{f}, \mathbf{h}-\mathbf{j}$ transfected with $2 \mu \mathrm{g} / \mathrm{ml}$ LPS for $18 \mathrm{~h}$, mock transfected or left untreated (Unstim.) or c, e, g stimulated with $100 \mathrm{ng} / \mathrm{ml}$ LPS for $16 \mathrm{~h}$, followed by stimulation with $3 \mathrm{mM}$ ATP for $2 \mathrm{~h}$. b, c CASP11, CASP1, pro-IL-1 $\beta$, pro-IL-18 and f, $\mathbf{g}$ cleaved GSDMD and NLRP3 levels were detected in cell lysates; $\mathbf{d}$, e cleaved IL-1 $\beta$, cleaved IL-18 and cleaved CASP1 were detected in the cell culture supernatants by western blot. b, $\mathbf{c}, \mathbf{g}$ In all, $5 \mu \mathrm{g}$ or $\mathbf{f} 10 \mu \mathrm{g}$ of total cell lysate or $\mathbf{d}, \mathbf{e}$ In all, $15 \mu \mathrm{l}$ of TCA-precipitated supernatant was loaded per lane. $\mathbf{b}, \mathbf{c}, \mathbf{f}$, g $\beta$-tubulin and panERK were used as loading controls. Molecular weights of the pre-stained protein marker bands are indicated. b-g Data are representative of two independent experiments. h, i LPStransfected BMDMs were stained with propidium iodide (PI) and Hoechst and $\mathbf{h}$ pictures were taken from three different regions to calculate $\mathbf{i}$ the percentage of PI-positive cells. Quantifications are from three independent experiments. $\mathbf{j}$ Lactate dehydrogenase (LDH) was measured in cell culture supernatants after LPS transfection and data are presented as \% LDH release relative to the values of mocktransfected BMDMs. Data are pooled from six independent experiments. a, i, j Horizontal lines and error bars represent mean \pm SD. * $p \leq$ $0.05, * * p \leq 0.01, * * * p \leq 0.001, * * * * p \leq 0.0001$.

$T y k 2^{K 923 E}$ and $T y k 2^{-/-}$cells, CASP11 and cleaved GSDMD were barely detectable in LPS transfected Ifnar ${ }^{-/}$BMDMs, whereas levels of CASP1 and NLRP3 were similar to WT cells (Fig. 5a, b). Ifnarl ${ }^{-1-}$ BMDMs had increased intracellular levels of pro-IL-1 $\beta$ (Fig. 5a), which is in line with observations in response to extracellular LPS $[15,53]$. However, secreted IL-1 $\beta$ levels were not increased in Ifnarl $^{-1-}$ BMDMs, indicating reduced IL-1 $\beta$ processing and release (Fig. 5c). In line with a previous study using extracellular LPS [54], Ifnarl $^{-1-}$ BMDMs had decreased upregulation of pro-IL-18 upon LPS transfection (Fig. 5a). We did not detect IL-18 in the supernatants of Ifnarl $^{-1-}$ BMDMs (Fig. 5c), indicating that the release of biologically active IL-18 in response to intracellular LPS is completely dependent on IFNAR1. The frequency of PI-positive cells and the levels of LDH in the cell culture supernatants were clearly lower in LPS transfected Ifnarl $^{-1-}$ BMDMs (Fig. 5d, e and Supplementary Fig. 5). Ifngrl ${ }^{-/-}$ BMDMs did not differ from WT BMDMs (Fig. 5a-e and Supplementary Fig. 5).

Collectively, these data confirm that type I IFN signalling promotes the induction of CASP11 and non-canonical inflammasome-dependent IL-1 $\beta$ and IL-18 processing and release in macrophages.

\section{Type I IFN and IFN $\gamma$ promote the production of IL-1 $\beta$ and IL-18 in vivo}

Type I IFNs promote the production of IL- $1 \beta$ during LPSinduced endotoxemia [38], whereas the contribution of
IFN $\gamma$ to CASP11-dependent IL-1 $\beta$ production in vivo is unknown. IL-1 $\beta$ and IL-18 levels were strongly reduced in LPS-treated Ifnarl ${ }^{-/}$and Ifngrl ${ }^{-/}$mice at $16 \mathrm{~h}$ after treatment (Fig. 6a, b), although these defects were less pronounced than in $T y k 2^{K 923 E}$ and $T y k 2^{-/-}$mice (Fig. 2c). $\mathrm{TNF} \alpha$ levels were reduced in Ifnarl ${ }^{-/-}$and Ifngrl ${ }^{-/-}$mice, whereas IL-6 levels were reduced in Ifngrl ${ }^{-1-}$ but not Ifnar $1^{-/-}$mice (Fig. 6a, b). CASP11 levels in spleens from LPS-treated Ifnarl ${ }^{-/-}$mice were lower (Fig. 6c) but did not differ between Ifngrl ${ }^{-/-}$and WT mice (Fig. 6d). CASP1 levels neither changed upon LPS nor differed between mice of the three genotypes (Fig. 6c, d). Recognition of intracellular LPS by CASP11 is facilitated by guanylate binding proteins (GBPs) $[55,56]$. GBPs are classical IFNstimulated genes (ISGs) and are among the most strongly induced genes in response to IFN $\gamma$ [57]. Deletion of all GBPs on chromosome 3 (i.e. GBP1, GBP2, GBP3, GBP5 and GBP7) profoundly reduced the release of IL-1 $\beta$ during LPS-induced endotoxemia, whereas deletion of GBP2 alone had more modest effects $[38,58]$. However, GBP2 has a prominent role in CASP11 activation during Gram-negative bacterial infections [59]. Gbp2 mRNA levels were reduced in spleens from Ifngrl ${ }^{-/-}$mice after treatment with PBS or LPS (Fig. 6e). In line with the impaired production of IFN $\gamma$, LPS-induced upregulation of $G b p 2$ mRNA was impaired in spleens from $T y k 2^{K 923 E}$ and $T y k 2^{-/-}$mice (Fig. 6f).

Taken together, these data suggest that type I IFN, IFN $\gamma$ and TYK2 increase systemic levels of IL- $1 \beta$ and IL-18 during endotoxemia and that this correlates with a positive regulatory role on CASP11 and/or GBP2 expression in the spleen.

\section{Pharmacological inhibition of TYK2 in mouse and human macrophages leads to a dose-dependent reduction of CASP11 and CASP5 protein levels}

To complement our genetic data, we tested whether pharmacological inhibition of TYK2 in BMDMs impairs LPSinduced upregulation of CASP11. Treatment with the allosteric TYK2 inhibitor BMS-986165 [60] inhibited the upregulation of CASP11 in a dose-dependent manner (Fig. 7a). There are two homologs of CASP11 in humans: CASP4 and CASP5. CASP4 is constitutively expressed in many cell types [34], including peripheral blood mononuclear cells (PBMCs), monocytes and the monocyte/ macrophage cell lines U937 and THP-1, whereas CASP5 is transcriptionally upregulated by LPS, IFN $\alpha / \beta$ and IFN $\gamma$ [61-64]. Similar to its effects on CASP11, BMS-986165 dose-dependently inhibited upregulation of CASP5 in response to LPS in U937 macrophages. CASP4 was constitutively expressed and not further upregulated by LPS (Fig. 7b). 

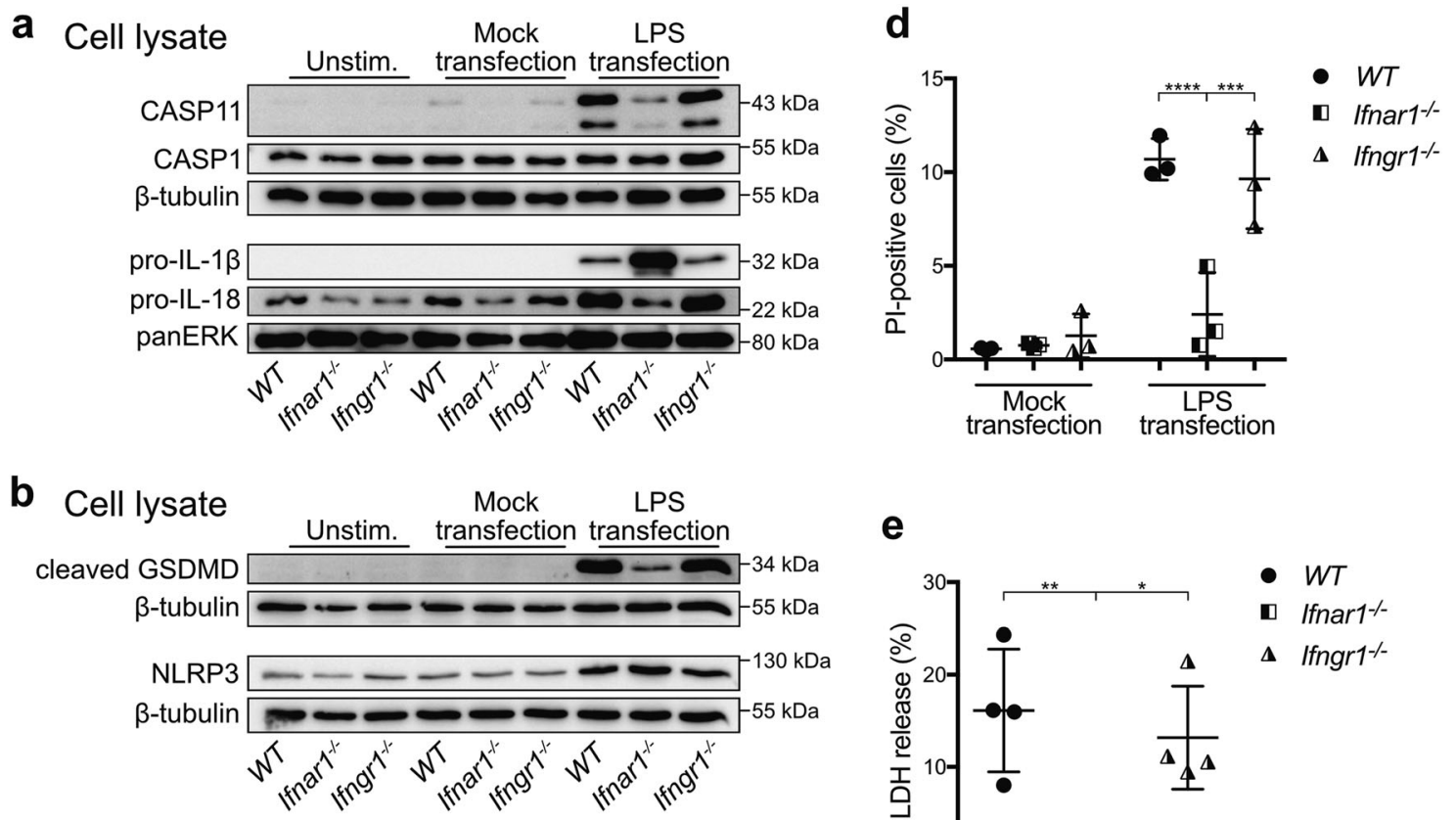

Cell culture
supernatant
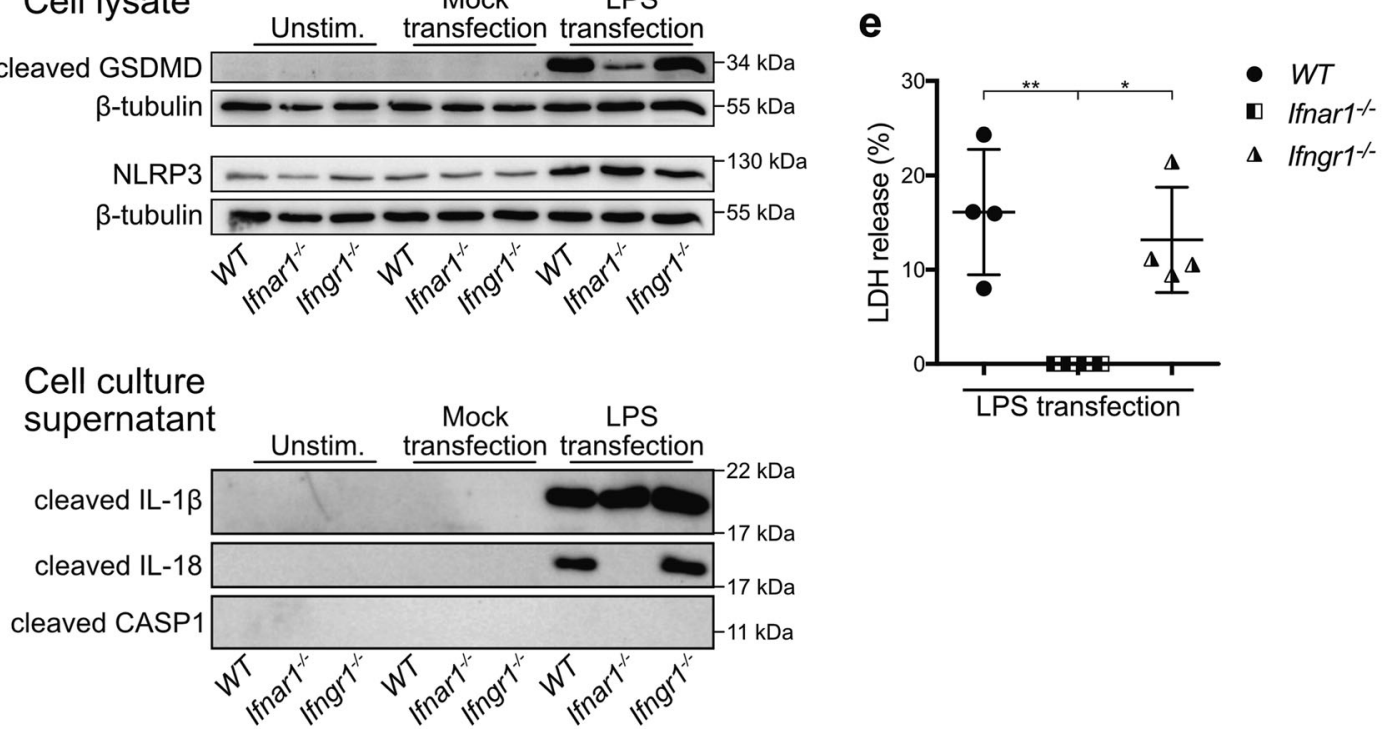

Fig. 5 Intact type I IFN signalling is required for the induction of CASP11 and the release of mature IL-1 $\beta$ and IL-18 in response to intracellular LPS. BMDMs from WT, Ifnarl ${ }^{-1-}$ and Ifngrl ${ }^{-1-}$ mice were transfected with $2 \mu \mathrm{g} / \mathrm{ml}$ LPS for $18 \mathrm{~h}$. a CASP11, CASP1, proIL- $1 \beta$, pro-IL-18 and $\mathbf{b}$ cleaved GSDMD and NLRP3 were detected in cell lysates; $\mathbf{c}$ cleaved IL-1 $\beta$, cleaved IL-18 and cleaved CASP1 were detected in cell culture supernatants by western blot. a In all, $5 \mu \mathrm{g}$ or $\mathbf{b}$ $10 \mu \mathrm{g}$ of total cell lysate or c $15 \mu \mathrm{l}$ of TCA-precipitated supernatant was loaded per lane. a, $\mathbf{b} \beta$-tubulin and panERK were used as loading controls. a-c Molecular weights of the pre-stained protein marker bands are indicated. Data are representative of two independent

Collectively, the data demonstrate that pharmacological inhibition of TYK2 impairs LPS-induced upregulation of CASP11 in murine and CASP5 in human macrophages.

\section{Discussion}

In this study we identified an essential role of kinase-active TYK2 in LPS-induced endotoxemia and non-canonical inflammasome activation in macrophages. Mechanistically, we show that TYK2 functions upstream of the induction of CASP11 and the release of mature IL-1 $\beta$ and IL-18. We experiments. d LPS-transfected BMDMs were stained with propidium iodide (PI) and Hoechst and pictures were taken from three different regions to calculate the percentage of PI-positive cells. Representative pictures are shown in Supplementary Fig. 5. Quantifications are pooled from three independent experiments. e Lactate dehydrogenase (LDH) was measured in cell culture supernatants after stimulation and data are presented as \% LDH release relative to the values of mock transfected BMDMs. Data are pooled from four independent experiments. d, e Horizontal lines and error bars represent mean \pm SD. $* p \leq 0.05$, ** $p \leq$ $0.01, * * * p \leq 0.001, * * * * p \leq 0.0001$.

propose that the impaired CASP11 availability contributes to the increased survival of $T y k 2^{-/-}$mice following LPSinduced endotoxemia, which is supported by the decreased LPS-induced lethality of $\mathrm{Casp}_{11^{-/-}}$and $111 \mathrm{~b}^{-/-} / I l 1 \mathrm{8}^{-/-}$ mice $[65,66]$. CASP11 has also been implicated in LPSinduced tissue injury $[38,67]$, suggesting that the decreased organ pathology in $T y k 2^{-/-}$mice may also reflect impaired upregulation of CASP11.

In support of our in vivo findings, we show that $T y \mathrm{k}^{-/-}$ BMDMs fail to upregulate CASP11 and show strongly reduced release of IL-1 $\beta$ and IL-18 in response to intracellular LPS. This is in stark contrast to the increased release of IL-1 $\beta$ and IL-18 in response to extracellular LPS 

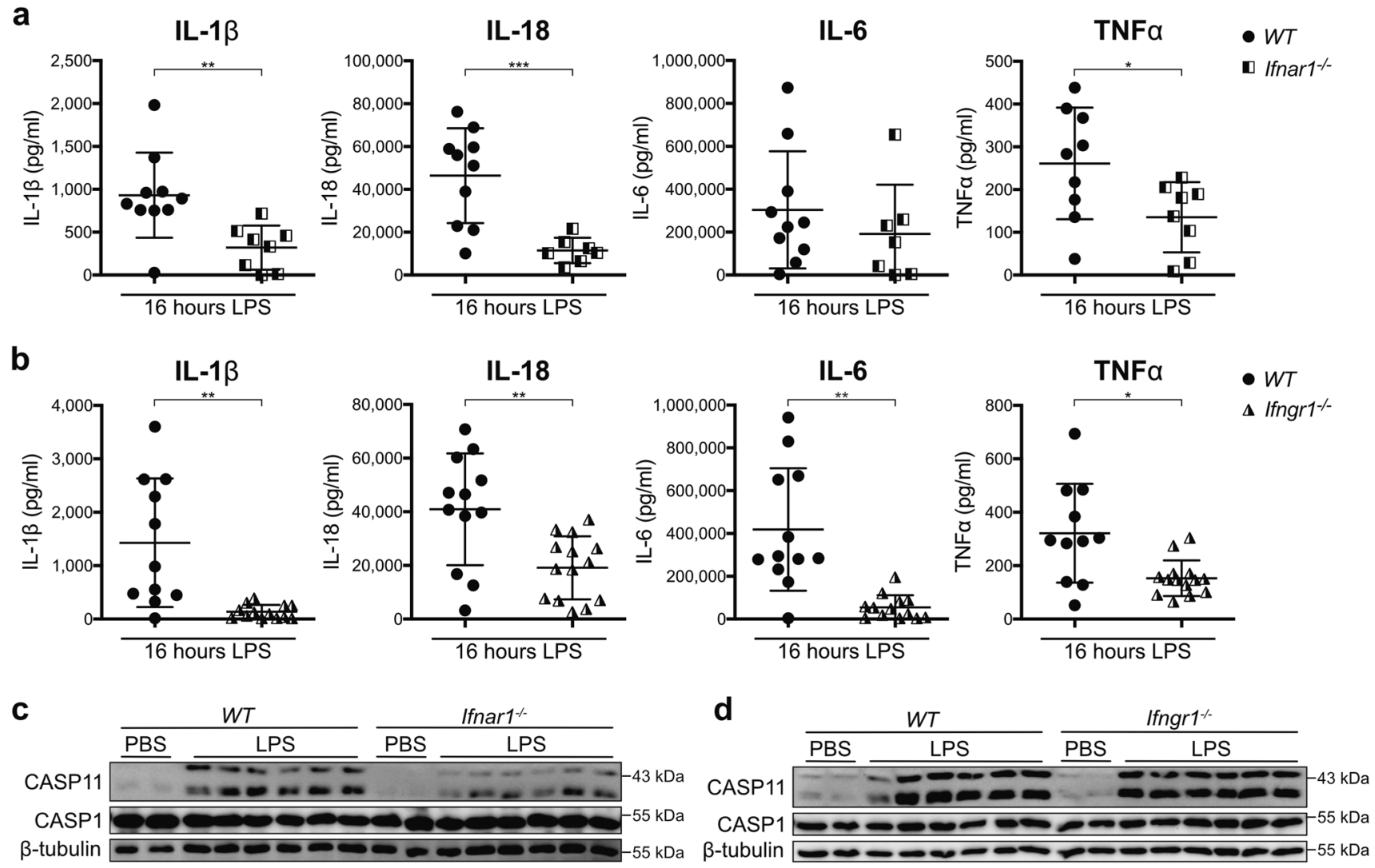

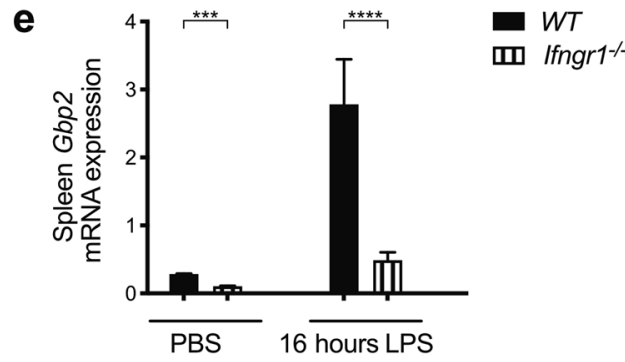

Fig. 6 Type I IFN and IFN $\gamma$ promote the production of IL-1及 and IL-18 in vivo. a, $\mathbf{c} W T$ and Ifnarl $^{-1-}, \mathbf{b}, \mathbf{d}, \mathbf{e} W T$ and $I f n g r 1^{-1-}$ or $\mathbf{f}$ $W T, T y k 2^{K 923 E}$ and $T y k 2^{-/-}$mice were injected i.p. with $50 \mathrm{mg} / \mathrm{kg}$ LPS. a, b Plasma levels of IL-1 $\beta$, IL-18, IL- 6 and TNF $\alpha$ were measured with Luminex bead-based multiplex assay after $16 \mathrm{~h}$. Data are pooled from two independent experiments a $(n=7-10 /$ genotype $), \mathbf{b}$ $(n=11-14 /$ genotype). Horizontal lines and error bars represent mean \pm SD. c, d $16 \mathrm{~h}$ after treatment, CASP 11 and CASP1 levels were determined in spleen lysates by western blot. In all, $15 \mu \mathrm{g}$ of total cell lysate was loaded per lane. $\beta$-tubulin was used as loading control.

and ATP [15] and clearly demonstrates that TYK2 positively and negatively impacts on the LPS-induced production of mature IL-1 $\beta$ and IL-18, depending on the type of inflammasome involved.

Previous studies with Ifnarl $^{-/-}$BMDMs indicated that CASP11 is induced by autocrine/paracrine IFN $\alpha / \beta$ signalling in response to LPS and infection with Gram-negative bacteria [51]. Our study supports these findings and suggests that CASP11 upregulation depends on an intact

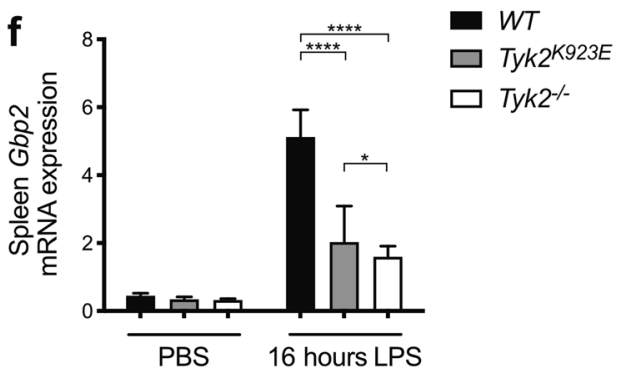

Molecular weights of the pre-stained protein marker bands are indicated. Data are representative of two independent experiments $(n=6 /$ genotype). e, f Spleens were harvested at $16 \mathrm{~h}$ after treatment and mRNA levels of Gbp2 were measured by RT-qPCR. Results are shown as relative expression compared to the housekeeping gene Ube $2 d 2$ and are given as mean \pm SD. Data are from $\mathbf{e}$ two independent experiments ( $n=12-14 /$ genotype) and $\mathbf{f}$ one representative out of two independent experiments $(n=6 /$ genotype $) .{ }^{*} p \leq 0.05, * * p \leq 0.01$, $* * * p \leq 0.001, * * * * p \leq 0.0001$.

IFNAR1-TYK2 axis, irrespective of whether LPS is applied intra- or extracellularly. Studies with Casp11 promoterreporter constructs and Stat $^{-/-}$BMDMs revealed a crucial role of STAT1 for the transcriptional induction of Casp11 in response to IFN $\gamma$ [52] and the IFNAR1-dependent upregulation of CASP11 upon infection with Salmonella typhimurium [68]. Thus, TYK2 most likely promotes the induction of Casp11 by amplifying STAT1 activation in response to $\mathrm{IFN} \alpha / \beta[17,19,69]$. 


\section{a Cell lysate} BMDMs

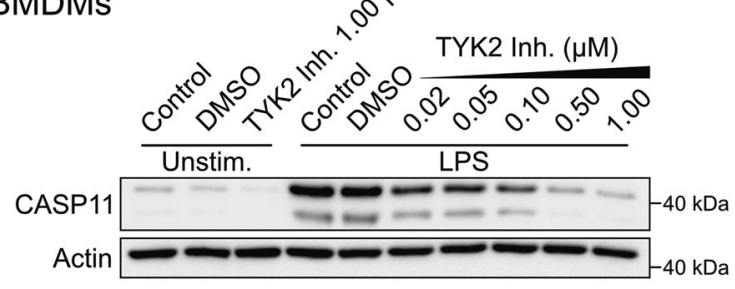

b Cell lysate

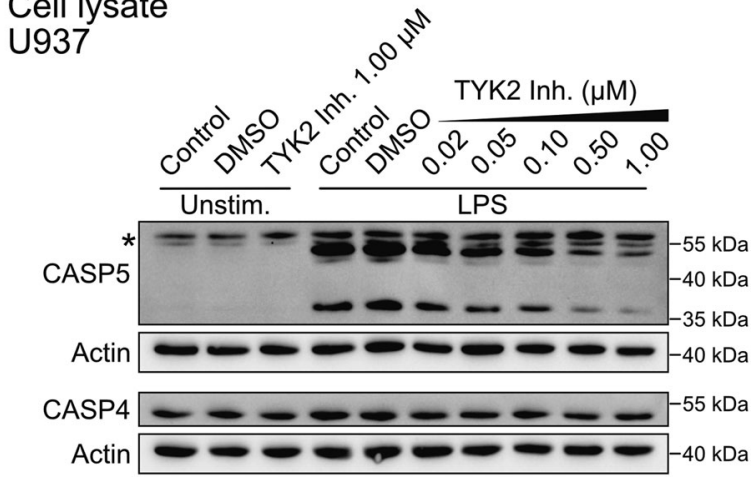

Fig. 7 Pharmacological inhibition of TYK2 in mouse and human macrophages leads to a dose-dependent reduction of CASP11 and CASP5 protein levels. a BMDMs from $W T$ mice or b PMAdifferentiated U937 macrophages were either stimulated with $100 \mathrm{ng} /$ $\mathrm{ml}$ LPS for $18 \mathrm{~h}$ or left unstimulated (Unstim.). a, b Cells were treated with the allosteric TYK2 inhibitor BMS-986165 (TYK2 Inh.) or with DMSO $(0.01 \% \mathrm{v} / \mathrm{v})$ as control. a CASP11 or b CASP5 and CASP4 were detected in cell lysates by western blot. a In all, $10 \mu \mathrm{g}$ or $\mathbf{b} 10 \mu \mathrm{l}$ of total cell lysate was loaded per lane $\mathbf{a}, \mathbf{b}$ Actin was used as loading control. Molecular weights of the pre-stained protein marker bands are indicated. Data are representative of two independent experiments. Asterisk indicates two unspecific bands in U937 cells.

In line with the findings in BMDMs, we show that IFNAR1-TYK2 signalling promotes the upregulation of CASP11 during endotoxemia in the spleen. This contrasts a previous report that showed unaltered CASP11 levels in splenocytes isolated from LPS-treated Ifnarl ${ }^{-/-}$mice [38]. The reason for this discrepancy is unclear, but might lie in the different dose or type of LPS used. In support of our data, this study also reported reduced systemic levels of IL- $1 \beta 16 \mathrm{~h}$ after LPS treatment in Ifnarl ${ }^{-/-}$and Caspl $1^{-/-}$mice.

Most of the studies on the non-canonical inflammasome have been conducted with macrophages. However, CASP11 and GSDMD are also expressed in non-myeloid cells, although some cell types, such as epithelial cells, lack a functional NLRP3 pathway and undergo pyroptosis without the release of mature IL-1 $\beta$ [47]. Using conditional Tyk2knockout mice, we provide evidence that myeloid cells are of prime importance for the TYK2-dependent release of IL$1 \beta$ and IL-18 during endotoxemia. In contrast, TYK2 activity in non-myeloid cells augments the production of TNF $\alpha$ and IL-6, underscoring that non-myeloid cells are relevant sources of these cytokines $[70,71]$.
Impaired IL-1 $\beta$ production in Ifnar $^{-/-}$mice during endotoxemia has been recently linked to an impaired induction of GBPs [38], although direct evidence was not provided. Our data suggest a role of IFN $\gamma$, at least for the induction of Gbp2 mRNA in the spleen. This is also supported by the fact that GBPs are more potently induced by IFN $\gamma$ than IFN $\alpha / \beta$ [57] and our finding that Ifngr ${ }^{-/-}$mice have reduced levels of IL-1 $\beta$ and IL-18, despite an unimpaired upregulation of splenic CASP11. GBPs facilitate the binding of intracellular LPS to CASP11 [47, 55, 56], raising the possibility that Ifngr $1^{-/-}$mice show reduced IL- $1 \beta$ and IL-18 production due to an impaired binding of LPS to CASP11. However, more detailed studies will be required to define the spatiotemporal contribution of type I IFNs and IFN $\gamma$ to the induction of CASP11 and GBPs. Our findings that $T y k 2^{-/-}$mice have strongly reduced serum levels of IFN $\gamma$ and reduced IFNGR1-dependent upregulation of splenic Gbp2 mRNA supports the concept that TYK2 also promotes the pathogenesis of endotoxemia through its involvement in the IL-12/IFN $\gamma$ axis [13].

Only a few studies exist on the role of the non-canonical inflammasome during infections with Gram-negative bacteria in vivo $[50,72,73]$. As TYK2 differentially affects the release of mature IL-1 $\beta$ upon canonical and non-canonical inflammasome activation, it seems reasonable to speculate that in the context of bacterially-induced sepsis, the consequences of TYK2 deficiency on inflammatory responses may depend on the bacterial community.

Another important finding of our study is that $T y k 2^{K 923 E}$ mice are phenotypically indistinguishable from $T y k 2^{-/-}$ mice, suggesting that kinase-active TYK2 drives LPSinduced pathogenesis. This goes in line with the requirement for enzymatically active TYK2 in the antiviral defense [19] but contrasts kinase-independent functions of TYK2 in NK cell-dependent tumour surveillance [8]. In support of our genetic data, we show that a TYK2-selective inhibitor [60] blocks LPS-induced upregulation of CASP11 in BMDMs and CASP5 in human macrophages. The second human CASP11 homolog CASP4 is constitutively expressed in most cell types [34] and not further upregulated by LPS [62]. Both CASP4 and CASP5 are activated by cytosolic LPS and capable of inducing pyroptosis [34]. However, the relative contribution to the pathogenesis of endotoxemia or bacterial sepsis is unclear [74]. Studies in mice have highlighted the involvement of CASP11-dependent inflammation in a wide spectrum of inflammatory diseases, such as rheumatoid arthritis, inflammatory bowel disease and neurodegenerative diseases [75]. Although there might be considerable redundancies in the functions of CASP4 and CASP5, our results raise the interesting possibility that inhibition of TYK2 may be an attractive therapeutic target for the treatment of CASP5-driven diseases. 
Collectively, we uncovered a fundamental role of TYK2 in the regulation of the non-canonical inflammasome. Our findings suggest that impaired upregulation of CASP11 and processing and release of IL- $1 \beta$ and IL-18 in the absence of TYK2 or its kinase activity contributes to the increased resistance against LPS-induced lethality.

Acknowledgements This work was supported by the Austrian Science Fund (FWF) project P25642-B22, DOC 32-B28 and the Special Research Program SFB-F6101, SFB-F6105 and SFB-F6106. AL is supported by the Deutsche Forschungsgemeinschaft (HeisenbergProfessorship, project number 24141047). We thank Marion Bokor for histological sample preparation, immunohistochemical staining and help with RT-qPCRs, Bettina Tutzer and Sara Lang for their help with in vivo experiments and Claus Vogl for help with the statistical analysis.

\section{Compliance with ethical standards}

Conflict of interest The authors declare that they have no conflict of interest.

Publisher's note Springer Nature remains neutral with regard to jurisdictional claims in published maps and institutional affiliations.

\section{References}

1. Fuchs S, Kaiser-Labusch P, Bank J, Ammann S, Kolb-Kokocinski A, Edelbusch $\mathrm{C}$, et al. Tyrosine kinase 2 is not limiting human antiviral type III interferon responses. Eur $\mathrm{J}$ Immunol. 2016;46:2639-49.

2. Kreins AY, Ciancanelli MJ, Okada S, Kong XF, Ramirez-Alejo N, Kilic SS, et al. Human TYK2 deficiency: Mycobacterial and viral infections without hyper-IgE syndrome. J Exp Med. 2015;212:1641-62.

3. Strobl B, Stoiber D, Sexl V, Mueller M. Tyrosine kinase 2 (TYK2) in cytokine signalling and host immunity. Front Biosci (Landmark Ed). 2011;16:3214-32.

4. Leitner NR, Witalisz-Siepracka A, Strobl B, Muller M. Tyrosine kinase 2 - Surveillant of tumours and bona fide oncogene. Cytokine. 2017;89:209-18.

5. He X, Chen X, Zhang H, Xie T, Ye XY. Selective Tyk2 inhibitors as potential therapeutic agents: a patent review (2015-2018). Expert Opin Ther Pat. 2019;29:137-49.

6. Papp K, Gordon K, Thaci D, Morita A, Gooderham M, Foley P, et al. Phase 2 trial of selective tyrosine Kinase 2 inhibition in psoriasis. N. Engl J Med. 2018;379:1313-21.

7. Li Z, Gakovic M, Ragimbeau J, Eloranta ML, Ronnblom L, Michel F, et al. Two rare disease-associated Tyk2 variants are catalytically impaired but signaling competent. J Immunol. 2013;190:2335-44.

8. Prchal-Murphy M, Witalisz-Siepracka A, Bednarik KT, Putz EM, Gotthardt D, Meissl K, et al. In vivo tumor surveillance by NK cells requires TYK2 but not TYK2 kinase activity. Oncoimmunology. 2015;4:e1047579.

9. Raje V, Derecka M, Cantwell M, Meier J, Szczepanek K, Sisler JD, et al. Kinase Inactive Tyrosine Kinase (Tyk2) supports differentiation of brown fat cells. Endocrinology. 2017;158:148-57.

10. Bosmann M, Ward PA. The inflammatory response in sepsis. Trends Immunol. 2013;34:129-36.

11. Buras JA, Holzmann B, Sitkovsky M. Animal models of sepsis: setting the stage. Nat Rev Drug Discov. 2005;4:854-65.
12. Bosmann M, Strobl B, Kichler N, Rigler D, Grailer JJ, Pache F, et al. Tyrosine kinase 2 promotes sepsis-associated lethality by facilitating production of interleukin-27. J Leukoc Biol. 2014;96:123-31.

13. Kamezaki K, Shimoda K, Numata A, Matsuda T, Nakayama K, Harada M. The role of Tyk2, Stat1 and Stat4 in LPS-induced endotoxin signals. Int Immunol. 2004;16:1173-9.

14. Karaghiosoff M, Steinborn R, Kovarik P, Kriegshauser G, Baccarini M, Donabauer B, et al. Central role for type I interferons and Tyk2 in lipopolysaccharide-induced endotoxin shock. Nat Immunol. 2003;4:471-7.

15. Radwan M, Stiefvater R, Grunert T, Sharif O, Miller I, MarchettiDeschmann $\mathrm{M}$, et al. Tyrosine kinase 2 controls IL- $1 \mathrm{~b}$ production at the translational level. J Immunol. 2010;185:3544-53.

16. Huang S, Hendriks W, Althage A, Hemmi S, Bluethmann H, Kamijo R, et al. Immune response in mice that lack the interferongamma receptor. Science. 1993;259:1742-5.

17. Karaghiosoff M, Neubauer H, Lassnig C, Kovarik P, Schindler H, Pircher H, et al. Partial impairment of cytokine responses in Tyk2deficient mice. Immunity. 2000;13:549-60.

18. Müller U, Steinhoff U, Reis LF, Hemmi S, Pavlovic J, Zinkernagel RM, et al. Functional role of type I and type II interferons in antiviral defense. Science. 1994;264:1918-21.

19. Prchal-Murphy M, Semper C, Lassnig C, Wallner B, Gausterer C, Teppner-Klymiuk I, et al. TYK2 kinase activity is required for functional type I interferon responses in vivo. PLoS ONE. 2012;7: e39141.

20. Vielnascher RM, Hainzl E, Leitner NR, Rammerstorfer M, Popp $\mathrm{D}$, Witalisz A, et al. Conditional ablation of TYK2 in immunity to viral infection and tumor surveillance. Transgenic Res. 2014;23:519-29.

21. Eilers A, Seegert D, Schindler C, Baccarini M, Decker T. The response of gamma interferon activation factor is under developmental control in cells of the macrophage lineage. Mol Cell Biol. 1993;13:3245-54.

22. Decker T, Lohmann-Matthes ML. A quick and simple method for the quantitation of lactate dehydrogenase release in measurements of cellular cytotoxicity and tumor necrosis factor (TNF) activity. $J$ Immunol Methods. 1988;115:61-69.

23. Rayamajhi M, Zhang Y, Miao EA. Detection of pyroptosis by measuring released lactate dehydrogenase activity. Methods Mol Biol. 2013;1040:85-90.

24. Bone RC, Balk RA, Cerra FB, Dellinger RP, Fein AM, Knaus WA, et al. Definitions for sepsis and organ failure and guidelines for the use of innovative therapies in sepsis. The ACCP/SCCM Consensus Conference Committee. American College of Chest Physicians/Society of Critical Care Medicine. Chest. 1992;101:1644-55.

25. Taveira da Silva AM, Kaulbach HC, Chuidian FS, Lambert DR, Suffredini AF, Danner RL. Brief report: shock and multiple-organ dysfunction after self-administration of Salmonella endotoxin. N. Engl J Med. 1993;328:1457-60.

26. Thiemermann C, Ruetten $\mathrm{H}$, Wu CC, Vane JR. The multiple organ dysfunction syndrome caused by endotoxin in the rat: attenuation of liver dysfunction by inhibitors of nitric oxide synthase. Br J Pharm. 1995;116:2845-51.

27. Emerson TE Jr., Fournel MA, Leach WJ, Redens TB. Protection against disseminated intravascular coagulation and death by antithrombin-III in the Escherichia coli endotoxemic rat. Circ Shock. 1987;21:1-13.

28. Boisson-Dupuis S, Ramirez-Alejo N, Li Z, Patin E, Rao G, Kerner $\mathrm{G}$, et al. Tuberculosis and impaired IL-23-dependent IFN-gamma immunity in humans homozygous for a common TYK2 missense variant. Sci Immunol. 2018;3:eaau8714.

29. Dejima T, Shibata K, Yamada H, Hara H, Iwakura Y, Naito S, et al. Protective role of naturally occurring interleukin- 
17A-producing gammadelta $\mathrm{T}$ cells in the lung at the early stage of systemic candidiasis in mice. Infect Immun. 2011;79:4503-10.

30. Ishizaki M, Muromoto R, Akimoto T, Sekine Y, Kon S, Diwan M, et al. Tyk2 is a therapeutic target for psoriasis-like skin inflammation. Int Immunol. 2014;26:257-67.

31. Ubel C, Graser A, Koch S, Rieker RJ, Lehr HA, Muller M, et al. Role of Tyk-2 in Th9 and Th17 cells in allergic asthma. Sci Rep. 2014;4:5865.

32. Gracey E, Hromadová D, Lim M, Qaiyum Z, Zeng M, Yao Y, et al. TYK2 inhibition reduces type 3 immunity and modifies disease progression in murine spondyloarthritis. J Clin Invest. 2020;130:1863-78.

33. Chan AH, Schroder K. Inflammasome signaling and regulation of interleukin-1 family cytokines. J Exp Med. 2020;217:e20190314.

34. Man SM, Kanneganti TD. Converging roles of caspases in inflammasome activation, cell death and innate immunity. Nat Rev Immunol. 2016;16:7-21.

35. Hagar JA, Powell DA, Aachoui Y, Ernst RK, Miao EA. Cytoplasmic LPS activates caspase-11: implications in TLR4independent endotoxic shock. Science. 2013;341:1250-3.

36. Kayagaki N, Wong MT, Stowe IB, Ramani SR, Gonzalez LC, Akashi-Takamura S, et al. Noncanonical inflammasome activation by intracellular LPS independent of TLR4. Science. 2013;341:1246-9.

37. Man SM, Karki R, Briard B, Burton A, Gingras S, Pelletier S, et al. Differential roles of caspase-1 and caspase-11 in infection and inflammation. Sci Rep. 2017;7:45126.

38. Tang Y, Zhang R, Xue Q, Meng R, Wang X, Yang Y, et al. TRIF signaling is required for caspase-11-dependent immune responses and lethality in sepsis. Mol Med. 2018;24:66.

39. Kayagaki N, Warming S, Lamkanfi M, Vande Walle L, Louie S, Dong $\mathrm{J}$, et al. Non-canonical inflammasome activation targets caspase-11. Nature. 2011;479:117-21.

40. Hsi ED, Remick DG. Monocytes are the major producers of interleukin-1 beta in an ex vivo model of local cytokine production. J Interferon Cytokine Res. 1995;15:89-94.

41. Yasuda K, Nakanishi K, Tsutsui H. Interleukin-18 in Health and Disease. Int J Mol Sci. 2019;20:649.

42. Madej MP, Topfer E, Boraschi D, Italiani P. Different regulation of Interleukin-1 production and activity in monocytes and macrophages: innate memory as an endogenous mechanism of IL-1 inhibition. Front Pharm. 2017;8:335.

43. Kayagaki N, Stowe IB, Lee BL, O'Rourke K, Anderson K, Warming $\mathrm{S}$, et al. Caspase-11 cleaves gasdermin $\mathrm{D}$ for noncanonical inflammasome signalling. Nature. 2015;526:666-71.

44. Broz P, Pelegrín P, Shao F. The gasdermins, a protein family executing cell death and inflammation. Nat Rev Immunol. 2020;20:143-57.

45. Shi J, Zhao Y, Wang K, Shi X, Wang Y, Huang H, et al. Cleavage of GSDMD by inflammatory caspases determines pyroptotic cell death. Nature. 2015;526:660-5.

46. Heilig R, Dick MS, Sborgi L, Meunier E, Hiller S, Broz P. The Gasdermin-D pore acts as a conduit for IL-1beta secretion in mice. Eur J Immunol. 2018;48:584-92.

47. Rathinam VAK, Zhao Y, Shao F. Innate immunity to intracellular LPS. Nat Immunol. 2019;20:527-33.

48. Guarda G, Braun M, Staehli F, Tardivel A, Mattmann C, Förster I, et al. Type I interferon inhibits interleukin-1 production and inflammasome activation. Immunity. 2011;34:213-23.

49. Kopitar-Jerala N. The role of interferons in inflammation and inflammasome activation. Front Immunol. 2017;8:873.

50. Aachoui Y, Kajiwara Y, Leaf IA, Mao D, Ting JP, Coers J, et al. Canonical inflammasomes drive IFN-gamma to prime caspase-11 in defense against a cytosol-invasive bacterium. Cell Host Microbe. 2015;18:320-32.
51. Rathinam VA, Vanaja SK, Waggoner L, Sokolovska A, Becker C, Stuart LM, et al. TRIF licenses caspase-11-dependent NLRP3 inflammasome activation by gram-negative bacteria. Cell. 2012;150:606-19.

52. Schauvliege R, Vanrobaeys J, Schotte P, Beyaert R. Caspase-11 gene expression in response to lipopolysaccharide and interferongamma requires nuclear factor-kappa B and signal transducer and activator of transcription (STAT) 1. J Biol Chem. 2002;277:41624-30.

53. Guarda G, Braun M, Staehli F, Tardivel A, Mattmann C, Forster I, et al. Type I interferon inhibits interleukin-1 production and inflammasome activation. Immunity. 2011;34:213-23.

54. Zhu Q, Kanneganti TD. Cutting edge: distinct regulatory mechanisms control proinflammatory Cytokines IL-18 and IL1beta. J Immunol. 2017;198:4210-5.

55. Meunier E, Broz P. Interferon-induced guanylate-binding proteins promote cytosolic lipopolysaccharide detection by caspase- 11 . DNA Cell Biol. 2015;34:1-5.

56. Pilla DM, Hagar JA, Haldar AK, Mason AK, Degrandi D, Pfeffer $\mathrm{K}$, et al. Guanylate binding proteins promote caspase-11dependent pyroptosis in response to cytoplasmic LPS. Proc Natl Acad Sci USA. 2014;111:6046-51.

57. MacMicking JD. IFN-inducible GTPases and immunity to intracellular pathogens. Trends Immunol. 2004;25:601-9.

58. Finethy R, Luoma S, Orench-Rivera N, Feeley EM, Haldar AK, Yamamoto, $\mathrm{M}$ et al. Inflammasome activation by bacterial outer membrane vesicles requires guanylate binding proteins. MBio. 2017;8:e01188-17.

59. Meunier E, Dick MS, Dreier RF, Schurmann N, Kenzelmann Broz $\mathrm{D}$, Warming $\mathrm{S}$, et al. Caspase-11 activation requires lysis of pathogen-containing vacuoles by IFN-induced GTPases. Nature. 2014;509:366-70.

60. Wrobleski ST, Moslin R, Lin S, Zhang Y, Spergel S, Kempson J, et al. Highly selective inhibition of tyrosine Kinase 2 (TYK2) for the treatment of autoimmune diseases: discovery of the allosteric inhibitor BMS-986165. J Med Chem. 2019;62:8973-95.

61. Chen N, Ou Z, Zhang W, Zhu X, Li P, Gong J. Cathepsin B regulates non-canonical NLRP3 inflammasome pathway by modulating activation of caspase-11 in Kupffer cells. Cell Prolif. 2018;51:e12487.

62. Lin XY, Choi MS, Porter AG. Expression analysis of the human caspase-1 subfamily reveals specific regulation of the CASP5 gene by lipopolysaccharide and interferon-gamma. J Biol Chem. 2000;275:39920-6.

63. Shi J, Zhao Y, Wang Y, Gao W, Ding J, Li P, et al. Inflammatory caspases are innate immune receptors for intracellular LPS. Nature. 2014;514:187-92.

64. Viganò E, Diamond CE, Spreafico R, Balachander A, Sobota RM, Mortellaro A. Human caspase-4 and caspase-5 regulate the onestep non-canonical inflammasome activation in monocytes. Nat Commun. 2015;6:8761.

65. Vanden Berghe T, Demon D, Bogaert P, Vandendriessche B, Goethals A, Depuydt B, et al. Simultaneous targeting of IL-1 and IL-18 is required for protection against inflammatory and septic shock. Am J Respir Crit Care Med. 2014;189:282-91.

66. Wang S, Miura M, Jung YK, Zhu H, Li E, Yuan J. Murine caspase-11, an ICE-interacting protease, is essential for the activation of ICE. Cell. 1998;92:501-9.

67. Ye Z, Zhang L, Li R, Dong W, Liu S, Li Z, et al. Caspase-11 mediates pyroptosis of tubular epithelial cells and septic acute kidney injury. Kidney Blood Press Res. 2019;44:465-78.

68. Broz P, Ruby T, Belhocine K, Bouley DM, Kayagaki N, Dixit $\mathrm{VM}$, et al. Caspase-11 increases susceptibility to Salmonella infection in the absence of caspase-1. Nature. 2012;490:288-91.

69. Shimoda K, Kato K, Aoki K, Matsuda T, Miyamoto A, Shibamori $\mathrm{M}$, et al. Tyk2 plays a restricted role in IFN alpha signaling, 
although it is required for IL-12-mediated $\mathrm{T}$ cell function. Immunity. 2000;13:561-71.

70. Sedger LM, McDermott MF. TNF and TNF-receptors: from mediators of cell death and inflammation to therapeutic giantspast, present and future. Cytokine Growth Factor Rev. 2014;25:453-72.

71. Rose-John S, Winthrop K, Calabrese L. The role of IL-6 in host defence against infections: immunobiology and clinical implications. Nat Rev Rheumatol. 2017;13:399-409.

72. Aachoui Y, Leaf IA, Hagar JA, Fontana MF, Campos CG, Zak DE, et al. Caspase-11 protects against bacteria that escape the vacuole. Science. 2013;339:975-8.
73. Gurung P, Malireddi RK, Anand PK, Demon D, Vande Walle L, Liu Z, et al. Toll or interleukin-1 receptor (TIR) domaincontaining adaptor inducing interferon-beta (TRIF)-mediated caspase-11 protease production integrates Toll-like receptor 4 (TLR4) protein- and Nlrp3 inflammasome-mediated host defense against enteropathogens. J Biol Chem. 2012;287:34474-83.

74. Matikainen S, Nyman TA, Cypryk W. Function and regulation of noncanonical Caspase-4/5/11 inflammasome. J Immunol. 2020;204:3063-9.

75. Yi YS. Caspase-11 non-canonical inflammasome: emerging activator and regulator of infection-mediated inflammatory responses. Int J Mol Sci. 2020;21:2736. 